\title{
Misallocation and Financial Frictions: the Role of Long-Term Financing
}

\author{
Marios Karabarbounis \\ Federal Reserve Bank of Richmond \\ Patrick Macnamara* \\ University of Manchester
}

February 14, 2016

\section{PRELIMINARY-PLEASE DO NOT CIRCULATE}

\begin{abstract}
This paper analyzes the effect of financial frictions on misallocation when firms can issue long-term bonds and can default on their obligations. Our model combines the endogenous investment, firm-financing structure of Hennessy and Whited (2007) with the long-term financing model of Hatchondo and Martinez (2009). We show that when investment is endogenous and firms issue long-term debt, productive firms can face as severe borrowing constraints as the low productivity firms. This occurs because good firms are more likely to refinance and hence "dilute" their existing debt obligations. A key step of our exercise is that we match the large cross-sectional dispersion in credit spreads we observe in the data. In our model productivity loss due to misallocation is about $10 \%$ which is 2.5 times higher compared to a model with short-term financing or exogenous collateral constraints.
\end{abstract}

Keywords: long-term bonds, debt dilution, financial frictions, misallocation

\footnotetext{
*Contact information: marios.karabarbounis@rich.frb.org and patrick.macnamara@manchester.ac.uk. Any opinions expressed are those of the authors and do not necessarily reflect those of the Federal Reserve Bank of Richmond or the Federal Reserve System.
} 


\section{Introduction}

A growing literature assigns productivity differences between countries, firms, or establishments to recourse misallocation. For example, Hsieh and Klenow (2009) use data on Chinese and Indian establishments and show that recourse misallocation accounts for 30-60\% of the TFP difference between these counties and U.S. productivity. The natural question posed by the same literature is what are the driving forces behind recourse misallocation. Financial frictions seems a natural candidate and has indeed been the focus of numerous papers (Gilchrist, Sim, and Zakrajsek (2012), for example).

Nonetheless, in an influential paper, Midrigan and Xu (2014) showed that financial frictions cannot generate large efficiency losses due to misallocation. In their paper, financial frictions take the form of exogenous borrowing (collateral) constraints. Firms can accumulate internal funds over time in order to grow out of their borrowing constraint. Since high productivity firms are more likely to quickly grow out of their constraint relative to low productivity firms, misallocation is limited.

We re-evaluate the effect of financial frictions on misallocation through the lens of a structural model of firm financing. In our model, firms borrow using defaultable bonds and invest in physical capital subject to adjustment costs. They also have the option to raise external equity (Hennessy and Whited (2007)). In this setup financial frictions take the form of bankruptcy losses in the case of default. Due to these losses creditors charge a premium over the risk-free rate to borrowers with a relatively higher probability of default. Our innovation is the introduction of long-duration bonds within this endogenous investment model. Long-duration bonds are modeled following Hatchondo and Martinez (2009) and Chatterjee and Eyigungor (2012). In particular, we assume that firms promise a geometrically declining sequence of payments to bond-holders. Each period a bond can mature with some probability in which case the firm pays lenders' the principal.

We show that long-term financing can affect substantially the ability of firms - and in particular which firms exactly - can issue debt. What matters with long-term financing is the sequence of productivity draws until the bond matures. With sufficiently low persistence in productivity, current productivity is a poor predictor of whether the firm will avoid default in the future. Hence, for all firms access to borrowing (and thus investment) may be limited. It turns out that highly productive firms may face even more severe borrowing constraints.

This occurs because lenders recognize that good firms may have access to cheap borrowing in the future and may be tempted to "dilute" existing debt obligations. For these reasons, in our model, firms cannot easily grow out of their constraints and find it hard to finance their investment. 
We test our model using firm-level data on daily bond issuances which we merge with data from Compustat. We show that our benchmark model can match well the cross-sectional distribution of credit spreads we observe in the data. This is important since the dispersion in credit spreads can be linked to the dispersion in the marginal product of capital (Gilchrist, Sim, and Zakrajsek (2012)), a key statistic to measure misallocation. The median credit spread is $2.8 \%$ in our model while $2.4 \%$ in the data. The standard deviation in our model is $1.53 \%$ which is a little lower than the $2.17 \%$ we see in the data. In sharp contrast, a model with a one-period bond generates a degenerate distribution close to zero.

We find that the TFP loss due to misallocation is around 10\% in our benchmark model. In contrast, a model with a one period bond or an exogenous borrowing constraint generates misallocation around $4.0 \%$. This is in most part due to a higher dispersion in the marginal product of capital: in our benchmark model the dispersion is twice as high as in the one period/exogenous constraint model. Using as a measure of misallocation the expected TFP loss - a measure which nets out any distortion arising from uncertainty over next period's productivity - we can get even larger differences between our benchmark and the one period model. In particular, our benchmark model can generate misallocation around 16 times higher $(6.5 \%$ versus $0.4 \%)$.

Our paper highlights the role of persistence in productivity for misallocation. Similar to Midrigan and $\mathrm{Xu}$ (2014), Moll (2014) notes that a firm can undo financial frictions by accumulating its internal funds. If productivity shocks are relatively persistent then a productive firm can quickly go out of its constraint. In contrast, if productivity shocks are transitory, financial frictions can lead to large losses. Our model strengthens the insights in Moll (2014) by stressing the importance of long-term financing. If current productivity is a good predictor of whether the firm will avoid default in the future then creditors might be less reluctant to lend cheaply to a productive firm. In contrast, if productivity is iid then both productive and unproductive firms will face approximately the same borrowing cost, as what matters is the ability to pay the coupon up to the maturity.

Our paper is also related with the work of Khan and Thomas (2013). The authors highlight the importance of adjustment costs for misallocation. Large costs to adjust investment might result to firms not being able to invest their first-best. We also model adjustment costs and hence incorporate this type of mechanism. However, we find that with long-term bonds there is another channel that decreases misallocation in the presence of adjustment costs. Creditors are reluctant to lend money to firms in fear of debt dilution. If firms face severe adjustment costs then it is less likely that the firm will sharply change its capital (and hence its borrowing opportunities) until the bond matures. So in our framework, adjustment costs can reduce misallocation in capital. 


\section{Model}

Our model combines the firm financing structure of Hennessy and Whited (2007) with the long-duration bonds literature: Hatchondo and Martinez (2009) and Chatterjee and Eyigungor (2012). In this model firms borrow for two reasons: (i) internal funds may be insufficient to reach the optimal level of investment, (ii) there is a tax benefit associated with debt which makes even unconstrained firms seek debt financing. The main cost associated with debt financing is the deadweight losses that occur in the event of default.

\section{$2.1 \quad$ Firms}

Firms are perfectly competitive and produce a single homogeneous good. The firm's profits are assumed to be $\pi(z, k)=z k^{\alpha}-c_{f}$, where $z$ is an idiosyncratic productivity shock, $k$ is the capital input, and $c_{f}$ is a fixed operating cost. The process for idiosyncratic productivity follows an $\mathrm{AR}(1)$ process:

$$
\ln z^{\prime}=\rho_{z} \ln z+\varepsilon
$$

where $\varepsilon$ is an i.i.d. shock drawn from $N\left(0, \sigma_{\varepsilon z}^{2}\right)$. We denote by $F\left(z^{\prime} \mid z\right)$ and $f\left(z^{\prime} \mid z\right)$ the cumulative distribution and probability density functions for next period's productivity $z^{\prime}$, conditional on the current productivity $z$.

\subsection{Sources of Financing for Investment}

The firm finances next period's capital using three sources: (1) internal equity, (2) external equity and (3) debt. Building on Hatchondo and Martinez (2009) and Chatterjee and Eyigungor (2012), we assume firms issue bonds that promise a geometrically declining sequence of payments. Specifically, suppose the firm had issued $b$ units of a bond in the previous period. Each bond will pay a coupon rate of $c$ and a fraction $\theta$ will mature this period. For the $\theta b$ bonds that mature, the firm pays back the principal plus interest, so that the total payment is $(1+c) \theta b$. For the $(1-\theta) b$ bonds that do not mature, the firm only pays the coupon, so that the total payment is $c(1-\theta) b$. The total payment from both is then $(\theta+c) b$. Since only a fraction $\theta$ of existing bonds mature today, the tomorrow's stock of bonds, $b^{\prime}$, must satisfy

$$
b^{\prime}=(1-\theta) b+x_{b}
$$

where $x_{b}$ is the new issuance of bonds. Let $q\left(z, k^{\prime}, b^{\prime}\right)$ be the price at which the firm is able to sell these bonds, so that the firm receives $q\left(z, k^{\prime}, b^{\prime}\right)\left[b^{\prime}-(1-\theta) b\right]$. This expression summa- 
rizes the debt dilution problem present when firms borrow long term. A larger issuance of bonds $b^{\prime}$ will likely demand a higher credit spread - a lower $q\left(z, k^{\prime}, b^{\prime}\right)$ - which decreases the dollar amount of current bonds issued. However, it also dilutes the current stock of bonds issued in the past. If bonds mature after one period (as in Hennessy and Whited (2007)) there is no such trade-off.

We describe the other ways a firm can finance investment by examining its budget constraint. Every period, the firm starts with an initial level of capital, $k$, and an outstanding stock of long-duration debt, $b$. The firm finances $k^{\prime}$ subject to the following budget constraint:

$$
d+k^{\prime}=e(z, k, b)+q\left(z, k^{\prime}, b^{\prime}\right)\left[b^{\prime}-(1-\theta) b\right]-g\left(k, k^{\prime}\right)
$$

where $d$ is dividends, $g\left(k, k^{\prime}\right)$ are the capital adjustment costs which take the form

$$
g\left(k, k^{\prime}\right)= \begin{cases}\left(\phi_{1}^{+}-1\right)\left(k^{\prime}-(1-\delta) k\right)+\frac{\phi_{2}}{2} \frac{(k-k)^{2}}{k} & \text { if } k^{\prime}>(1-\delta) k \\ \left(1-\phi_{1}^{-}\right)\left(k^{\prime}-(1-\delta) k\right)+\frac{\phi_{2}}{2} \frac{(k-k)^{2}}{k} & \text { if } k^{\prime}<(1-\delta) k\end{cases}
$$

and

$$
e(z, k, b)=\pi(z, k)-T_{c}[\pi(z, k)-\delta k-c b]+(1-\delta) k-(\theta+c) b
$$

is the firm's short-term internal equity. $T_{c}[\pi(z, k)-\delta k-c b]$ denote the corporate income taxes. When $d>0$, the firm is issuing dividends to shareholders (and shareholders separately pay the dividend tax rate $\tau_{d}$ ). When $d<0$, the firm is raising funds directly from shareholders. This, however, is costly as shareholders must also pay an equity issuance cost assumed to be a fraction $\lambda$ of the amount of equity raised. $\Lambda(d)$ is a function which reflects the equity issuance cost when $d<0$ and the dividend tax when $d>0$ :

$$
\Lambda(d)=\left\{\begin{array}{cl}
-\lambda d & \text { if } d<0 \\
\tau_{d} d & \text { if } d \geq 0
\end{array}\right.
$$

Therefore, when choosing $k^{\prime}$, the firm has access to three sources of funding: (1) longduration debt (i.e., $\left.q\left(z, k^{\prime}, b^{\prime}\right)\left(b^{\prime}-(1-\theta) b\right)\right)(2)$ internal equity (i.e., $\left.e(z, k, b)\right)$, and $(3)$ external equity (when $d<0$ ).

\subsection{Tax System}

Three taxes are considered in this paper. The first is the tax on interest income. Investors must pay a constant tax rate rate, $\tau_{i}$, on interest income. The second tax is that shareholders must pay a flat tax rate, $\tau_{d}$, on dividends. And finally, the third tax is that firms must pay a tax on their corporate income. The firm's taxable income, $x$, is assumed to be profits minus 
economic depreciation and interest expense:

$$
x=\pi(z, k)-\delta k-c b
$$

where $\delta$ is the depreciation rate of capital and $c b$ is the interest in expense. As mentioned, since interest expenses are subtracted by taxable income, firms have an incentive to borrow even if they have sufficient internal funds. Then, given a taxable income of $x$, the firm's total corporate tax bill is given by

$$
T_{c}(x) \equiv \int_{0}^{x} \tau_{c}(y) d y
$$

where $\tau_{c}(y)$ is the marginal corporate income tax rate at income $y$.

\subsection{Value Functions and Default Decision}

Every period after the realization of $z$, the firm can choose whether to default or continue its operations.

Value of Default If the firm defaults the shareholders receive nothing and the firm is liquidated. Hence

$$
V_{D}=0
$$

Value of exit The value of exit, $V_{x}(z, k, b)$, is defined to be:

$$
V_{x}(z, k, b)=d-\Lambda(d)
$$

where

$$
d=e(z, k, b)-q_{x}(1-\theta) b-g(k, 0)
$$

Therefore, when the firm is forced to exit (exogenously), it distributes to shareholders what's remaining of the firm's internal equity, after buying back its un-matured debt at the price $q_{x}$ and paying the capital adjustment cost $g(k, 0)$.

Value of No Default A firm that does not default chooses $k^{\prime}$ and $b^{\prime}$ optimally according to the following program:

$$
V(z, k, b)=\max _{d, k^{\prime}, b^{\prime}}\left\{d-\Lambda(d)+\frac{\gamma}{1+r\left(1-\tau_{i}\right)} E\left[V_{n d}\left(z^{\prime}, k^{\prime}, b^{\prime}\right), 0\right]\right\}
$$


subject to

$$
\begin{aligned}
d+k^{\prime} & =e(z, k, b)+q\left(z, k^{\prime}, b^{\prime}\right)\left[b^{\prime}-(1-\theta) b\right]-g\left(k, k^{\prime}\right) \\
e(z, k, b) & =\pi(z, k)-T_{c}[\pi(z, k)-\delta k-c b]+(1-\delta) k-(\theta+c) b
\end{aligned}
$$

The parameter $\gamma \in(0,1]$ reflects the extra impatience of the firm. If the firm chooses not to default, with probability $\eta$, the firm will still exit (exogenously). Therefore, we also define the value function

$$
V_{n d}\left(z^{\prime}, k^{\prime}, b^{\prime}\right)=(1-\eta) V\left(z^{\prime}, k^{\prime}, b^{\prime}\right)+\eta V_{x}\left(z^{\prime}, k^{\prime}, b^{\prime}\right)
$$

where $V\left(z^{\prime}, k^{\prime}, b^{\prime}\right)$ is the value the firm receives if it does not exit, while $V_{x}\left(z^{\prime}, k^{\prime}, b^{\prime}\right)$ is the value the firm receives if it exits (and does not default).

Default Threshold In general, we can define a threshold, $z_{d}^{\prime}\left(k^{\prime}, b^{\prime}\right)$, such that the firm will default next period only for realizations of productivity $z^{\prime}<z_{d}^{\prime}\left(k^{\prime}, b^{\prime}\right)$. This threshold is defined to be the value of idiosyncratic productivity, $z_{d}^{\prime}$, such that the firm is just indifferent between defaulting and not defaulting:

$$
V_{n d}\left(z_{d}^{\prime}, k^{\prime}, b^{\prime}\right)=0
$$

Consequently, this default threshold will depend on the firm's chosen levels of capital $k^{\prime}$ and debt $b^{\prime}$.

\subsection{Bond Price}

The firm issues bonds which are purchased by risk-neutral lenders. In our model financial frictions take the form of bankruptcy costs. In the case of default, the lender is assumed to pay a bankruptcy cost, $B\left(k^{\prime}\right)$ :

$$
B\left(k^{\prime}\right)=\psi\left[(1-\delta) k^{\prime}-g\left(k^{\prime}, 0\right)\right]
$$

Since defaulting firms are liquidated, the lender then recovers $R\left(z^{\prime}, k^{\prime}\right)$ :

$$
R\left(z^{\prime}, k^{\prime}\right)=\pi\left(z^{\prime}, k^{\prime}\right)-T_{c}\left[\pi\left(z^{\prime}, k^{\prime}\right)-\delta k^{\prime}\right]+(1-\psi)\left[(1-\delta) k^{\prime}-g\left(k^{\prime}, 0\right)\right]
$$

It is well documented that bondholders usually recover only a fraction of liquidated firms. We view the fraction $(1-\psi)$ as representing this recovery rate. The lender receives the stock 
of capital remaining after bankruptcy costs, as well as the after-tax profits of the firm. However, consistent with the US tax code, interest deductions are dis-allowed in default.

The importance of long-term debt shows up when the firm does not default. In these states, the lender receives $(\theta+c)$ for each bond. However, with long-duration debt, a fraction $(1-\theta)$ of the bonds have not matured, and the value of those bonds tomorrow depends on tomorrow's price $q^{\prime}\left(z^{\prime}, k^{\prime}, b^{\prime}\right)$ and hence tomorrow's debt issuance $b^{\prime}$. The lenders will take this into account when charging the firm a credit premium.

Overall, the price of the bond, $q\left(z, k^{\prime}, b^{\prime}\right)$ is set to guarantee the lender an expected return equal to the risk free rate:

$$
q\left(z, k^{\prime}, b^{\prime}\right)=\frac{1}{1+r}\left[\frac{1}{b^{\prime}} \int_{0}^{z_{d}^{\prime}\left(k^{\prime}, b^{\prime}\right)} R\left(z^{\prime}, k^{\prime}\right) f\left(z^{\prime} \mid z\right) d z^{\prime}+D\left(z, k^{\prime}, b^{\prime}\right)\right]
$$

where

$$
D\left(z, k^{\prime}, b^{\prime}\right)=\int_{z_{d}^{\prime}\left(k^{\prime}, b^{\prime}\right)}^{\infty}\left[\theta+c+q^{\prime}\left(z^{\prime}, k^{\prime \prime}, b^{\prime \prime}\right)(1-\theta)\right] f\left(z^{\prime} \mid z\right) d z^{\prime}
$$

and $q^{\prime}\left(z^{\prime}, k^{\prime \prime}, b^{\prime \prime}\right)=(1-\eta) q\left(z^{\prime}, k^{\prime \prime}\left(z^{\prime}, k^{\prime}, b^{\prime}\right), b^{\prime \prime}\left(z^{\prime}, k^{\prime}, b^{\prime}\right)\right)+\eta q_{x}$.

The first term inside the brackets captures the usual payoff to the lender in default states. This is the main component driving the credit spread variations in one-period bond models. However, with long-duration bonds we also have a "dilution" component, $D\left(z, k^{\prime}, b^{\prime}\right)$. The key idea in this expression is that the current price $q$ depends on the future price $q^{\prime}$, so on the future choices of capital and debt and on the future probability of default. Hence, the first component reflects the probability of default one period ahead while the second the probability of default in all future states until the bond matures.

\subsection{New Entrants}

To model entry we follow Clementi and Palazzo (2016) and Katagiri (2014) and assume that there is a fixed pool of potential entrants, where the mass of potential entrants is normalized to one. Each potential entrant draws an initial productivity, $z$, from the cumulative distribution function $G(z)$. In the calibration, this function is assumed to be the invariant distribution for idiosyncratic productivity. If the potential entrant chooses to enter, it will immediately invest. However, the firm starts with no capital and no debt, and therefore does not produce in the period it enters. After the potential entrant chooses to enter, it pays a fixed entry cost $c_{e}$.

In making its entry decision, a potential entrant compares the value it would receive from operating against the total cost of entry. Therefore, potential entrants will enter if 
and only if $V(z, 0,0) \geq c_{e}$. As with default, we can define a threshold, $z_{e}$, such that only potential entrants with $z \geq z_{e}$ will choose to enter. This threshold is defined to be the value of productivity, $z_{e}$, such that

$$
V\left(z_{e}, 0,0\right)=c_{e}
$$

Consequently, there will be selection on entry, and only the most productive potential entrants will choose to enter.

\subsection{Alternative Models}

Our model features (i) endogenous default and (ii) long-term financing. We highlight the importance of both assumptions by considering two alternative models. The first is a model with an exogenous borrowing (collateral) constraint (named "Exogenous Constraint" Model). We assume that borrowing is limited up to a fraction of tomorrow's expected profits and un-depreciated capital: $b^{\prime} \leq \psi_{c}+\psi_{z} z+\psi_{k} k^{\prime}$. This is similar to the specification in Midrigan and $\mathrm{Xu}$ (2014), with the addition of a constant. In this model the bond price schedule is given by

$$
q\left(z, k^{\prime}\right)=\left\{\begin{array}{cl}
\frac{1+c}{1+r} & \text { if } b^{\prime} \leq \psi_{c}+\psi_{z} z+\psi_{k} k^{\prime} \\
0 & \text { if } b^{\prime}>\psi_{c}+\psi_{z} z+\psi_{k} k^{\prime}
\end{array}\right.
$$

The second model we consider is a model with endogenous default but short-term financing. This model keeps the exact same structure as our benchmark model with the exception that $\theta=1$, The model corresponds closely to Hennessy and Whited (2007). We will refer to this model as "One-period Bond" Model.

\section{Model Analysis}

The magnitude of misallocation refers to the ability of productive firms to raise funds and undertake their desired investment. In this section we discuss how the presence of longterm financing affects the allocation of resources between productive and unproductive firms.

Optimal Financing and Investment Policy: We start our analysis by explaining what determines the firm's optimal financing and investment policies. The first order conditions 
for $k^{\prime}$ and $b^{\prime}$ are

$$
\begin{array}{r}
\beta \int_{z_{d}^{\prime}}^{\infty} V_{k}\left(z^{\prime}, k^{\prime}, b^{\prime}\right) h\left(z^{\prime} \mid z\right) d z^{\prime}=\left(1-\Lambda^{\prime}(d)\right)\left[1-\frac{\partial q}{\partial k^{\prime}}\left(b^{\prime}-(1-\theta) b\right)+\frac{\partial g\left(k, k^{\prime}\right)}{\partial k^{\prime}}\right] \\
\left(1-\Lambda^{\prime}(d)\right) \frac{\partial}{\partial b^{\prime}}\left\{q\left(z, k^{\prime}, b^{\prime}\right)\left(b^{\prime}-(1-\theta) b\right)\right\}=-\beta \int_{z_{d}^{\prime}}^{\infty} V_{b}\left(z^{\prime}, k^{\prime}, b^{\prime}\right) h\left(z^{\prime} \mid z\right) d z^{\prime}
\end{array}
$$

To characterize the derivatives of the value function, $V_{k}(z, k, b)$ and $V_{b}(z, k, b)$, we apply the Envelope theorem to obtain:

$$
\begin{aligned}
& V_{k}(s, k, b)=\left(1-\Lambda^{\prime}(d)\right)\left[\frac{\partial}{\partial k}\left\{\pi(s, k)-T_{c}[\pi(s, k)-\delta k-c b]\right\}+(1-\delta)-\frac{\partial g\left(k, k^{\prime}\right)}{\partial k}\right] \\
& V_{b}(s, k, b)=\left(1-\Lambda^{\prime}(d)\right)\left[c \tau_{c}(\pi(s, k)-\delta k-c b)-(\theta+c)-q\left(s, k^{\prime}, b^{\prime}\right)(1-\theta)\right]
\end{aligned}
$$

Interpretation of first order condition for $k^{\prime}$ : The left-hand side of Equation 2 depicts the marginal benefit of the additional investment, while the right-hand side depicts the marginal cost. Holding $b^{\prime}$ fixed, the additional investment decreases dividends by $x=1-\frac{\partial q}{\partial k^{\prime}}\left[b^{\prime}-(1-\theta) b\right]+\frac{\partial g\left(k, k^{\prime}\right)}{\partial k^{\prime}}$. If the firm is currently issuing dividends (i.e., $\left.d>0\right)$, shareholders pay a lower dividend tax. Therefore, the marginal cost to the shareholder of the additional investment is $\left(1-\tau_{d}\right) x$. However, if the firm is currently issuing equity (i.e., $d<0$ ), the firm must raise an additional $x$ units of equity. Since this is costly, the marginal cost to the shareholder is $(1+\lambda) x$. On the other hand, the marginal benefit to the firm is the increased value that shareholders receive tomorrow in non-default states (which they discount by $\beta$ ). The marginal increase in value tomorrow reflects several things. First note that this marginal increase in value depends on whether the firm is issuing equity or issuing dividends tomorrow. If the firm is expected to be in an equity-issuance regime tomorrow, the marginal benefit will be higher. The marginal benefit will reflect the increased after-tax profits tomorrow, but will also reflect the additional capital adjustment costs that will have to be paid tomorrow.

Interpretation of first order condition for $b^{\prime}$ : At the margin if the firm were to issue an additional bond, it would raise an additional $x=q+\frac{\partial q}{\partial b^{\prime}}\left[b^{\prime}-(1-\theta) b\right]$ funds from the bond market. If the firm is currently issuing equity (i.e., $d<0$ ), this allows the firm to substitute away from costly external equity. The firm is therefore able to reduce its equity issuance by $x$, and also to reduce the equity issuance cost by $\lambda x$. Therefore, in this case, the marginal benefit of the additional borrowing is $(1+\lambda) x$. However, if the firm is currently issuing dividends (i.e., $d>0$ ), this implies that shareholders receive an additional $x$ dividends. However, since shareholders must pay a tax on those dividends, the marginal 
benefit is now $\left(1-\tau_{d}\right) x$. The marginal cost of the additional borrowing is the reduced value in non-default states tomorrow, which they discount by $\beta$. This is reflected in the right-hand side of Equation 3. This marginal value $V_{b}\left(s^{\prime}, k^{\prime}, b^{\prime}\right)$ tomorrow reflects several things. First, the value depends on whether the firm will be in an equity issuance regime or dividend issuing regime tomorrow. Second, the additional debt reduces the corporate income tax that the firm has to pay tomorrow (this is reflected in the term $c T_{c}^{\prime}$ ). Third, the additional borrowing increases the burden of the debt tomorrow (in non-default states) by $\theta+c+q\left(s^{\prime}, k^{\prime \prime}, b^{\prime \prime}\right)(1-\theta)$, where $q\left(s^{\prime}, k^{\prime \prime}, b^{\prime \prime}\right)$ is the price of the debt tomorrow.

Long-term debt and investment: We show how long-term debt can exacerbate financial frictions and affect the firms' investment choice causing misallocation. Wy simplify the first order condition for $k^{\prime}$ by assuming (1) that there are no taxes (i.e., $\tau_{d}=\tau_{i}=\tau_{c}=0$ ), (2) equity issuance costs are zero (i.e, $\lambda=0$ ), (3) there are no capital adjustment costs (i.e., $\left.g\left(k, k^{\prime}\right)=0\right)$ and $(4) \gamma=1$. In this case, the first order condition for $k^{\prime}$ becomes

$$
E\left[\frac{\partial \pi\left(z^{\prime}, k^{\prime}\right)}{\partial k^{\prime}} \mid z\right]=r+\delta+\underbrace{\int_{0}^{z_{d}^{\prime}}\left[\frac{\partial \pi\left(z^{\prime}, k^{\prime}\right)}{\partial k^{\prime}}+1-\delta\right] h\left(z^{\prime} \mid z\right) d z^{\prime}-(1+r) \frac{\partial q}{\partial k^{\prime}}\left[b^{\prime}-(1-\theta) b\right]}_{W=\text { wedge }}
$$

The wedge represents the effect of financial frictions on investment. The term $\int_{0}^{z_{d}^{\prime}}\left[\frac{\partial \pi\left(z^{\prime}, k^{\prime}\right)}{\partial k^{\prime}}+1-\delta\right] h\left(z^{\prime} \mid z\right) d z^{\prime}$ is associated with the probability of default. If firms default then they will lose their investment. The term $(1+r) \frac{\partial q}{\partial k^{\prime}}\left[b^{\prime}-(1-\theta) b\right]$ is associated with the link between the firm's investment and the credit spread it pays to the lenders.

To understand why long-term debt can affect the optimal investment and misallocation consider the case where $b^{\prime} \rightarrow 0$. In this case $z_{d}^{\prime}=0$ since there is no reason the firm would choose to default (and lose its capital/profits) next period. If $\theta=1$ then capital $k^{\prime}$ would be chosen at the point where the expected marginal product of capital equals $r+\delta$. Implicit in this argument is that the equity issuance costs are zero so that even low internal fund firms can invest their first-best level. In such a case the wedge is zero.

However, when $\theta<1$, in spite of $b^{\prime} \rightarrow 0$, there is a wedge between the expected marginal product of capital and $r+\delta$. The wedge is related to the firm being able to affect its credit spreads through investment and hence affect its outstanding debt $b$. For this reason (and as we will show later in the quantitative analysis), the credit spreads will always start from a higher level with long-term financing relative to a one-period bond.

Financial Frictions and Misallocation: We exploit the first order condition for capital to link misallocation and financial frictions. We have shown that we can simplify the first 
order condition for capital to

$$
E\left[\frac{\partial \pi\left(z^{\prime}, k^{\prime}\right)}{\partial k^{\prime}} \mid z\right]=r+\delta+W
$$

where $W$ represent the wedge associated with financial frictions. Assuming the $z$ is heterogeneous across firms but constant over time $\left(z^{\prime}=z\right)$ we have that

$$
k^{\prime}=\left[\frac{r+\delta+W}{a z}\right]^{\frac{1}{a-1}}
$$

Aggregate TFP is defined as TFP $=\frac{Y}{K^{a}}$ where $Y$ is aggregate output and $K$ is aggregate capital. To measure aggregate output $Y$ we aggregate over all firms' output $y_{i}$

$$
Y=\int_{i} y_{i}=\int_{i} z_{i} k_{i}^{a}=c \int_{i} z_{i}^{\frac{1}{1-a}}\left[r+\delta+W_{i}\right]^{\frac{a}{a-1}}
$$

where $c=\left[\frac{1}{a}\right]^{\frac{a}{a-1}}$. Similarly we aggregate over individual firms' capital $k_{i}$ to find aggregate capital

$$
K=\int_{i} k_{i}=c^{\frac{1}{a}} \int_{i} z_{i}^{\frac{1}{1-a}}\left[r+\delta+W_{i}\right]^{\frac{1}{a-1}}
$$

As a result we can write total factor productivity as

$$
T F P=\frac{\int_{i} z_{i}^{\frac{1}{1-a}}\left[r+\delta+W_{i}\right]^{\frac{a}{a-1}}}{\left[\int_{i} z_{i}^{\frac{1}{1-a}}\left[r+\delta+W_{i}\right]^{\frac{1}{a-1}}\right]^{a}}
$$

The three statistics that will affect $T F P$ is the dispersion in productivity $\sigma_{z}$, the dispersion in the wedge $\sigma_{W}$ (which will affect the dispersion in the MPK) and finally the covariance between the productivity and the wedge $\operatorname{Cov}\left(z_{i}, W_{i}\right)$. Note that the literature assumes joint log-normality between these random variables so that the covariance drops out. However in our case this will not be the case which will have implications on misallocation. Intuitively, if high productivity firms can easily access the borrowing market, they will face a smaller wedge (negative covariance). In this case misallocation will be limited. If high productivity firms face severe borrowing constraints then the covariance will be positive and misallocation will be larger. 


\section{Empirical Analysis}

The purpose of this section is to present some stylized facts regarding corporate bond issuance, credit spreads, investment and financial characteristics. We will focus on the cross-section of firms. We will use these cross-sectional patterns to discipline and test our quantitative model. To construct stylized facts on corporate bond issuance and investment we combine two firm-level datasets. The first is the Thomson-Reuters... This data includes daily information on primary issuances of corporate bonds. In particular, the data provide information (among others) on the name of the firm issuing the bond, the amount raised from the deal, the issue date, the type and purpose of the bond issuance, the maturity of the bond and the spread over a similar maturity T-Bill.

Table ?? reports summary statistics for corporate bond issuance, for the period between 2000 - 2013. The total number of bond deals is 18,728. The average amount raised in a bond deal is $\$ 196.2$ million. To compute the average we weight each deal by its amount relative to the total amount issued in the given year. Moreover, we find that the average bond deal matures in 11.4 years with a standard deviation of 8.2 years. This means that the majority of bond financing involves long-term issuances. The Table also reports the average credit spread of a deal which is the spread over a T-Bill of a similar maturity. The average credit spread is around $2.5 \%$. but there is substantial dispersion: the standard deviation is $2.1 \%$. To understand better the large dispersion in credit spreads we also plot the credit spread distribution.

Table 1: Bond Deals (Table) and Credit Spread Distribution (Figure)

Bond Deal Statistics (Average and Standard Deviation)

\begin{tabular}{lc} 
Amount (\$Millions) & 196.2 \\
Maturity (Years) & $(189.0)$ \\
& 11.4 \\
Credit Spread (over T-Bill) & $(8.2)$ \\
& $2.5 \%$ \\
$\#$ Deals & $(2.1 \%)$ \\
\hline \hline
\end{tabular}

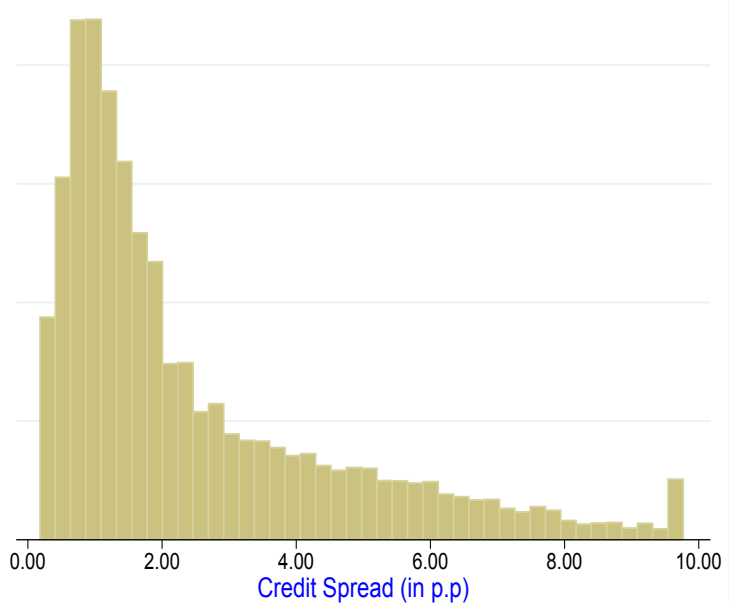

Note: The Table reports summary statistics for Bond Deals for the period 2000-2013. The Figure plots the credit spread distribution over the same period. Source: Thomson-Reuters.

Using the distribution of bond deals we construct an expected default rate of corporate 
Table 2: Summary Statistics: Sales and Investment

\begin{tabular}{lcc} 
Statistic & Mean & St. Deviation \\
\hline Persistence in log-sales & 0.81 & 0.42 \\
Investment Rate & 7.4 & 8.0 \\
$\quad<1 \%$ (inaction) & 0.08 & - \\
$\quad>20 \%$ (spike) & 0.15 & - \\
\hline \hline
\end{tabular}

Note: The Table reports summary statistics regarding persistence in log-sales and investment rates. Source: Compustat (2000-2013).

bonds. In particular, more than half of the firms/bonds deals are rated by Moody's. As an example, in our sample, $20 \%$ of bond deals are rated as A1, $15 \%$ as Baa1, $12 \%$ as Baa2, and $10 \%$ as A3. We use Moody's estimates on default probabilities of each class of bonds to measure an average default rate. We choose the probability of defaulting after 12 years since this is the average maturity in our sample. We find that the average default rate of bonds in our sample is $1.56 \%$.

The second firm-level dataset is Compustat which includes financial information on publicly-held companies. We exclude financial firms and utilities as these industries are more heavily regulated. We also exclude firms affected by a merger or an acquisition. We are left with 138,018 firm/year observations.

We use this sample to estimate two set of statistics. The first is the persistence in sales. We will use this moment to discipline the productivity process in the model. In particular, we estimate a first-order autoregressive process for firm-level log-sales. We control for the year and the firm industry. The persistence in log-sales equals 0.81 while the standard deviation equal to 0.42. We define the investment rate as investment funds used for additions to property, plants and equipment divided by total assets. We define the "Inaction" region as an investment rate less than $1 \%$. We find that around $8 \%$ belong to this group. We define a "Spike" in investment if the investment is above $20 \%$ which corresponds to the $90^{\text {th }}$ percentile in our data. We find that around $15 \%$ belong to this group. The average investment rate is $7.4 \%$ and the standard deviation is $8.0 \%$.

When we merge Compustat with our bond issuance dataset we are left with 5,320 bond deal observations. The average amount raised in this subsample is $\$ 236$ million substantially larger than the average amount including all bond deal. This is not surpising as Compustat firms are publicly listed, typically large firms that can raise a larger amount of funds if they decide to borrow in the bond market. However, the average maturity and credit spread 
Table 3: Log Credit Spreads and Leverage: Regression (Table) and Scatterplot (Figure)

\begin{tabular}{lccc}
\hline \hline & $(1)$ & $(2)$ & $(3)$ \\
& Coef./SE & Coef./SE & Coef./SE \\
\hline \multirow{2}{*}{ Leverage } & $(0.06)$ & $(0.05)$ & $(0.06)$ \\
\hline Year F.E. & No & Yes & Yes \\
Controls & No & No & Yes \\
Adj-R2 & 0.16 & 0.39 & 0.74 \\
Observations & 5315 & 5315 & 3183 \\
\hline \hline
\end{tabular}

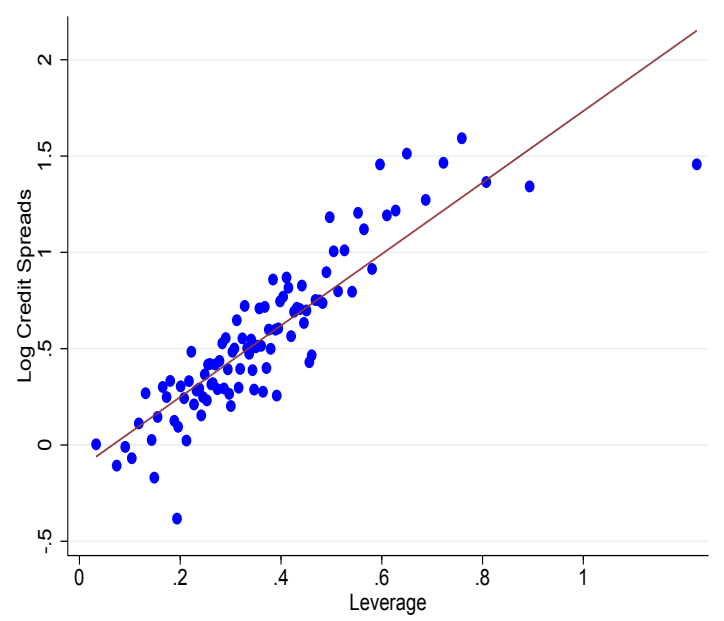

Note: The Table reports the estimates of a regression of log-credit spreads on leverage. The Figure is a scatter plot of log-credit spread and leverage. Source: Thomson-Reuters/Compustat.

are not substantially different. For Compustat firms the average bond deal matures in 10.8 years (relative to 11.4 in the whole sample) while the average credit spread is around $2.3 \%$ (relative to $2.5 \%$ in the whole sample).

We next analyze the relationship between credit spreads and firm leverage. We merge our bond issuance data with data on financial statements by Compustat. We define leverage as debt over assets. Total assets is the book value of assets (data item \#6). We define debt as the sum of debt in current liabilities (data item \#34) and long-term debt (data item \#9). The average leverage ratio is 0.28 in the data. We plot the relationship between log-credit spread and leverage in Figure 1. There is a strong positive relationship between the two variables. Firms that have higher leverage are asked to pay a premium when they borrow. To evaluate better this relationship we run the following regression:

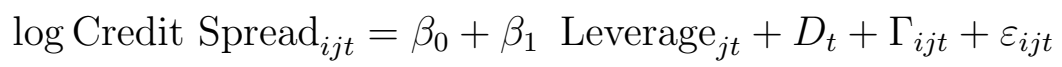

Credit $\operatorname{Spread}_{i t}$ is the spread paid for a deal $i$ by firm $j$ in period $t$. Leverage fis $_{t}$ ise leverage of firm $j$ in period $t$. $D_{t}$ are year dummies. $\Gamma_{i j t}$ is a set of firm and bond controls. As firm controls we include the firm rating by Moody and the firm's industry. As bond controls we include the amount issued, the bond maturity. We run the regression separately with and without controls in Table 2. All specifications the relationship is positive and significant. When we include both year dummies and firm/bond controls the coefficient is 0.57 . This means that if a firm increases its leverage by 1 percentage point it will pay $0.57 \%$ higher in credit spread. 


\section{Calibration}

In this section we describe the parameter values and our calibration strategy. One set of parameters are set externally based on values commonly set in the literature. Another set of parameters will be internally calibrated based on moments computed in the data. We will employ several statistics calculated in the empirical section described before.

Externally Set Parameters The model is computed at an annual frequency. We normalize the wage rate to 1 and set an annual risk-free rate of $4 \%$. The depreciation rate is set at $10 \%$, a value commonly employed in the literature. We abstract from exogenous exit rate for now and set $\eta=0, c_{f}=0$. Firms do exit endogenously though due to default.

We set the capital share equals $\alpha=0.675$. This is equivalent to having a firm which employed labor and maximizes profits:

$$
\pi(s, k)=\max _{n}[f(s, k, n)-w n]
$$

where the production function is now $f(s, k, n)=s\left[k^{\alpha} n^{(1-\alpha)}\right]^{\varepsilon}$. We use the values $\alpha * \varepsilon=0.27$, $(1-\alpha) * \varepsilon=0.6$ and $\varepsilon=0.87$ based on Khan and Thomas (2014) (cite?). In that case we will have $a=\frac{\alpha * \varepsilon}{(1-(1-\alpha) * \varepsilon)}$ which gives $a=0.675$. Substituting for optimal labor, profits can be written as $\pi=A * z * k^{a}$, where $z=s^{(1 /(1-(1-\alpha) * \varepsilon))}$ and wage is set to normalize $A=1$. We follow Khan and Thomas (2014) (cite?)and use $z=s^{(} 1 /\left(1-(1-a l p h a) * \varepsilon\right.$ and $\sigma_{e s}=0.118$. This gives $\rho_{z}=0.659, \sigma_{e z}=0.295$.

The expected maturity of a bond is $\sum_{t=1}^{\infty} t \theta(1-\theta)^{t-1}=1 / \theta$. Since the expected maturity in our data is 11.8 we set $\theta=0.084$. We set $c=r$ which is just a normalization to ensure the risk free $q=1$. Under this structure, if $b$ is the number of bonds issued in period $t$, then the promised payment in $p_{t}$ is equal to $p_{t}=(c+\theta)(1-\theta)^{t-1} b$. However, the promised payments are exactly the same as issuing $[(c+\theta) / \theta] b$ zero-coupon bonds.

Bankruptcy cost equals $\psi=0.25$ based on Arellano, Bai, and Zhang (2012). We also set exogenously the divident tax $\operatorname{tau}_{d}=0.12$ - a typical value in the literature - and the equity issuance cost $\lambda=0.059$ based on Hennessy and Whited (2007) . We intend to internally estimate this parameter later based on the frequency of equity issuance in the data.

We choose the following parametric form for our corporate income tax function:

$$
T_{c}=\left\{\begin{array}{lll}
\tau_{c_{\min }} * x & \text { if } & x<0 \\
\tau_{c_{\max }} * x & \text { if } & x \geq 0
\end{array}\right.
$$

where $x=\pi(z, k)-\delta k-c b$. As mentioned, deducting interest payments on debt gives 
an incentive for firms for positive leverage. Our tax function exhibits a kink which is typical in the literature. We set $\tau_{c_{\text {min }}}=0.2$ and $\tau_{c_{\text {max }}}=0.35$.

Internally Set Parameters We calibrate internally the remaining parameters based on moments computed in our empirical section. We discipline the patience parameter $\gamma$ to target the median credit spread in the data. If the firm discounts the future at low rates (low $\gamma$ ) then incentives to default are higher. Creditors acknowledge this and charge a higher credit spread. Finally, we choose $\phi_{1}^{-}, \phi_{2}$ to match (1) the frequency of firms in the inaction region $(|i / k<1 \%|)$ and $(2)$ the cross-sectional standard deviation of investment rates.

\section{Quantitative Analysis}

We describe in this section the basic quantitative properties of our model. We focus on how the credit spreads (bond price schedule) are affected by changes in productivity.

Probability of Default: Short vs. Long Horizon The higher the probability of default the higher credit spread charged by the creditors. To understand how long-term financing affects the credit spread we plot in Figure 1 the probability of default as a function of $b^{\prime}$. In our long-term framework each firm can issue a bond which matures each period with probability $\theta$. Hence, we can distinguish between the probability of default in the short-run (next couple of periods, for example) from the probability of default over a longer horizon (10 years ahead). Figure 1 makes this distinction. Note that in the one-period bond model (Hennessy and Whited (2007)) only the left panel is in effect as the bond matures with probability $\theta=1$ after 1 period.

In all horizons the default probability increases with a higher debt issuance $b^{\prime}$. A highly indebted firm will have smaller value and hence will find default more attractive. More noteworthy is the relation between productivity and default probability. Intuitively, a more productive firm will invest more so that default will become less attractive. At the same time, a (currently) productive firm can find easy access to future credit and might be more likely to end up in defaulting states in the future. Implicit in this argument is a relatively low persistence in the productivity process. While the former channel is always in effect, the latter is true only for the case of a long-term financing. Indeed, we see that the default probability decreases in $z$ when the bond matures after one period. In this case, current productivity is a good predictor of whether the firm will default in the next period. However, as the time-horizon of the bond grows a productive firm might face a higher probability of default. 
Figure 1: Probability of Default
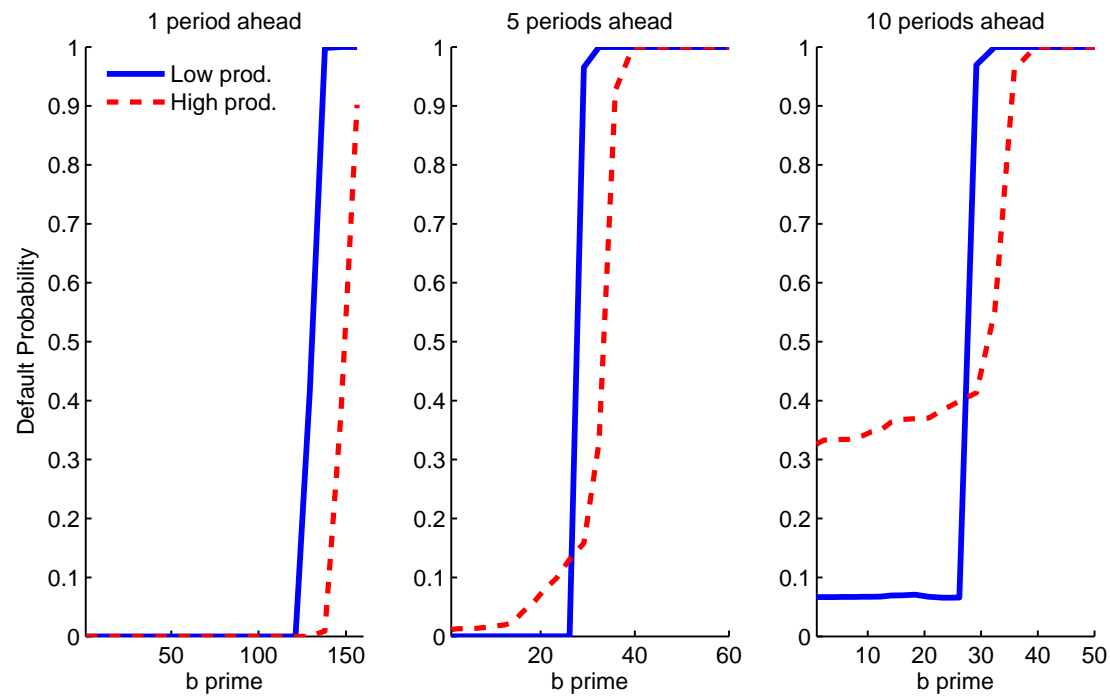

Note: This figure plots the probability of default across $b^{\prime}$ and $z$ for different time horizons: 1-period, 5 -period, and 10-period ahead. The one-period case is equivalent to $\theta=1$.

Bond Price Schedule The next step is to examine how the bond price schedule $q\left(z, k^{\prime}, b^{\prime}\right)$ is determined in the presence of long-term bonds. This is important as the dispersion of credit spread distribution will matter for the dispersion in the marginal product of capital.

Figure 2 plots the bond price schedule against $b^{\prime}$ for the case of a one-period bond $\theta=1$ and for our long-term bond model $\theta=0.085$. We plot the schedule for several values of $z$. With long-duration the bond price schedule differs substantially from the one-period bond. First, for low values of debt, the bond price starts out at a value less than 1 . This means that creditors will charge a premium even for low amounts of debt issuance. In the one-period bond model, firms can issue a small amount of debt at the risk-free price, which is normalized to 1 in this model.

Second, long-term maturity affects the slope of the bond price schedule. In the one-period bond creditors allow the firm to borrow at the risk-free rate up to some amount, after which they sharply increase the credit spread ( $q$ falls steeply). In our benchmark model, the slope of the bond price falls (in some but not all cases) more gradually. Moreover, the borrowing capacity of a firm is more limited in the long-duration bond case, as $q$ falls to zero for much lower values of $b^{\prime}$.

Therefore, there are two channels through which long-duration debt will generate credit spreads in equilibrium. The first is through the effect of the initial bond price as $b^{\prime}$ approaches 
Figure 2: Bond Price Schedule

Bond price, $\theta=1$

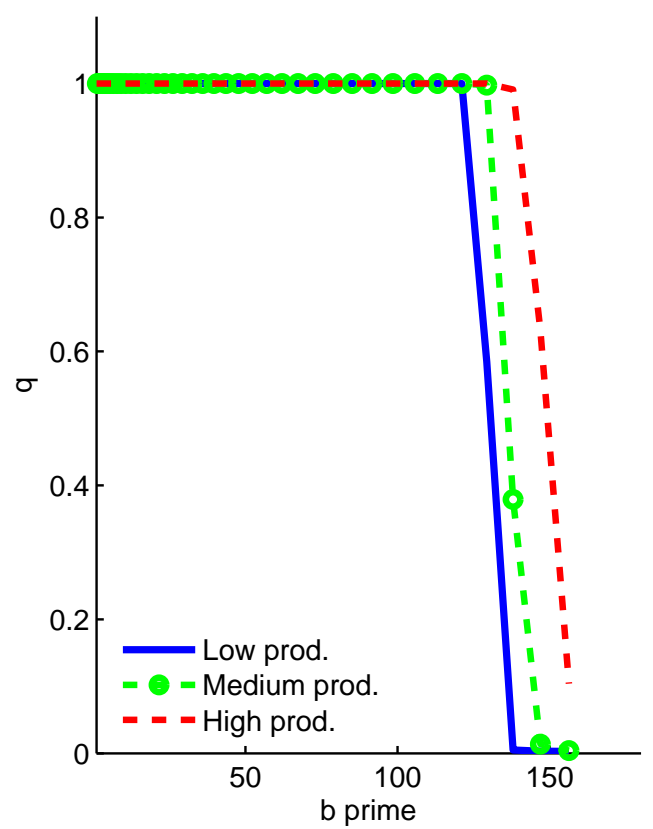

Bond price, $\theta=0.085$

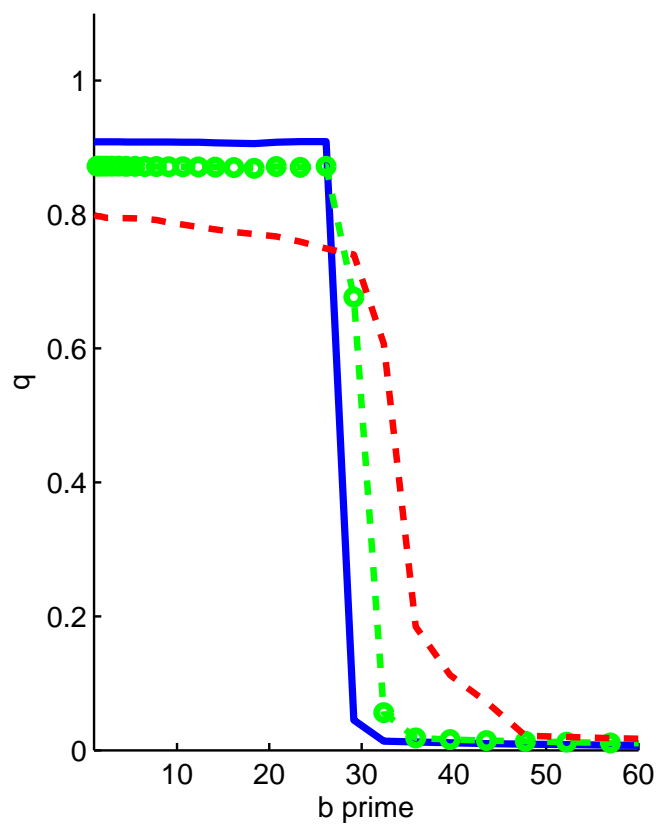

Note: This figure plots the bond price schedule across $b^{\prime}$ and $z$ for $\theta=1$ (Left Panel) $\theta=0.085$ (Right Panel)

zero. The second is through the effect of long-duration debt on the slope of $q\left(z, k^{\prime}, b^{\prime}\right)$. To understand why long-duration debt influences the bond price in these ways, it is useful to analyze the bond pricing equation defined in Equation 1 (repeated here for convenience):

$$
q\left(z, k^{\prime}, b^{\prime}\right)=\frac{1}{1+r}\left[\frac{1}{b^{\prime}} \int_{0}^{z_{d}^{\prime}} R\left(z^{\prime}, k^{\prime}\right)+D\left(z, k^{\prime}, b^{\prime}\right) f\left(z^{\prime} \mid z\right) d z^{\prime}\right]
$$

where

$$
D\left(z, k^{\prime}, b^{\prime}\right)=\int_{z_{d}^{\prime}}^{\infty}\left[\theta+c+q^{\prime}\left(z^{\prime}, k^{\prime}\left(z^{\prime}, k^{\prime}, b^{\prime}\right), b^{\prime}\left(z^{\prime}, k^{\prime}, b^{\prime}\right)\right)(1-\theta)\right] f\left(z^{\prime} \mid z\right) d z^{\prime}
$$

As mentioned, if $b^{\prime} \rightarrow 0$ then $z_{d}^{\prime}=0$ which further implies that $q\left(z, k^{\prime}, b^{\prime}\right)=$ $D\left(z, k^{\prime}, b^{\prime}\right) /(1+r)$. When $\theta=1, D\left(z, k^{\prime}, b^{\prime}\right)=1+c$, and therefore $q=1$ (since we assume $c=r$ ). However, when $\theta<1$, today's bond price may be less than one if tomorrow's bond price $q^{\prime}$ is expected to be less than one. Therefore, even though the probability of default is zero, the firm still pays a premium for its debt because of the possibility that the 
firm will make future investment and debt decisions which will lower the value of un-matured debt issued today.

The shape of the default probabilities (Figure 1) help us understand the slope of $q$. In the one-period bond case the default probability rises sharply toward one, once the firm exceeds a $b^{\prime}$ threshold. As a result, $q$ declines sharply toward zero. In the long-term bond case, $q$ will reflect the probability of default over many horizons. As $b^{\prime}$ increases more and more defaulting states will become likely which will gradually decrease $q$.

The relation between default probabilities and productivity help us analyze the relation between the bond price schedule (Figure 1) and productivity. For productive firms (that undertake high investments) the probability of default one period ahead is lower. This happens because the firm will not wish to lose its capital. However, if the firm can issue new debt in the future then lenders will take this into account when charging the firm a premium. It turns out that high $z$ firms will be more likely to borrow excessively in the future (i.e. choose a high $b^{\prime \prime}, b^{\prime \prime \prime}$ etc.) since they will able to refinance their debt relatively cheaply. This will make these firms more prone to financial distress relative to low $z$ who will not be able to find easy access to credit.

\section{Results}

\subsection{Credit Spreads}

We report in Table 4 some statistics from our benchmark model and compare them to the data. We also compare our benchmark to a model with a one-period bond $(\theta=1)$ and an exogenous collateral constraint. Our model captures the median credit spreads in the data ( $2.8 \%$ vs. $2.4 \%$ ). In contrast, in the one-period bond model the median credit spread is very low compared to the data. The benchmark also captures better the wide dispersion in the credit spreads. The standard deviation of credit spreads is $1.5 \%$ in our model versus $2.17 \%$ in the data. The one-period bond model misses the dispersion by a wide margin $(0.07 \%)$.

Figure 3 plots the credit spread distribution for the data, the benchmark model and the one-period bond. As mentioned, our model can generate substantial dispersion in the credit spreads close to the one in the data. The shape of the distributions is related to the bond price schedules (Figure 2). In the one period bond model the bond price falls very steeply after a $b^{\prime}$ threshold. This makes all firms choosing a $b^{\prime}$ so that they pay a rate approximately equal to the risk-free rate. In the long-term bond case the bond price schedules (i) start from different initial points, depending on productivity and (ii) decrease more gradual, which allows a wider dispersion in the credit spreads. 
Figure 3: Credit Spread Distributions
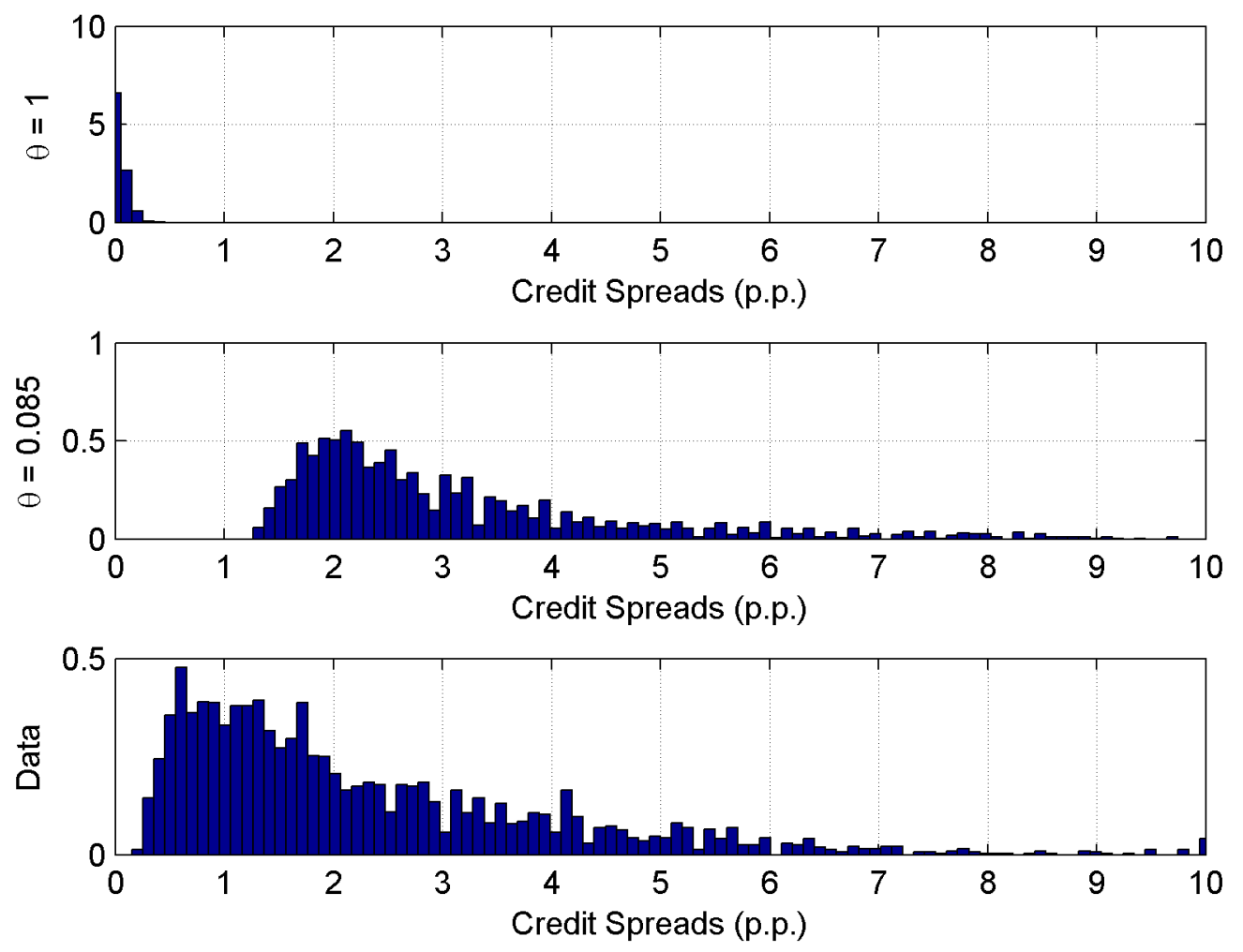

Note: The top panel plots the equilibrium distribution of credit spreads when $\theta=1$. The middle panel plots the credit spread distribution when $\theta=1 / 11.8$. The bottom panel shows the data from Thompson-Reuters.

Table 4: Model Statistics

Moment

Targeted Moments

Median Credit Spread

Untargeted Moments

St. Dev. of Credit Spread

Average Default Rate

$2.4 \% \quad 2.8 \%$

$0.03 \%$

$0 \%$

Data Benchmark One-period Bond Exogenous

$\begin{array}{llll}2.1 \% & 1.5 \% & 0.06 \% & 0 \% \\ 1.5 \% & 4.3 \% & 0.07 \% & 0 \%\end{array}$




\subsection{Calculating Misallocation}

We describe here how we compute TFP losses that arise due to the misallocation of capital and labor across firms. We provide more details of the derivations in the Appendix. To compute TFP losses, we take as given the total stock of capital $K=\int k d \mu$ and the total stock of labor $N=\int n d \mu$ in the economy. We then allocate capital and labor across firms to maximize total output, subject to the constraint that the same amount of aggregate capital and labor are used as in the original economy. In other words, taking as given the aggregate stock of capital $K$ and labor $N$ from the original economy, we solve the following problem:

$$
\max _{k_{i}, n_{i}} \sum_{i} s_{i} k_{i}^{\hat{\alpha}} n_{i}^{\hat{\beta}}
$$

subject to

$$
\begin{aligned}
& \sum_{i} k_{i}=K \\
& \sum_{i} n_{i}=N
\end{aligned}
$$

The solution to this problem requires that the marginal product of capital and the marginal product of labor are equated across firms. In this case, the efficient level of output will be given by

$$
Y_{e}=\Gamma^{1-\hat{\alpha}-\hat{\beta}} K^{\hat{\alpha}} N^{\hat{\beta}}
$$

where $\Gamma=\sum_{i} s_{i}^{1 /(1-\gamma)}$. $\Gamma^{1-\hat{\alpha}-\hat{\beta}}$ is the efficient level of TFP. We can derive the first-order conditions

$$
\begin{aligned}
& \hat{\alpha} s_{i} k_{i}^{\hat{\alpha}-1} n_{i}^{\hat{\beta}}=\lambda_{k} \\
& \hat{\beta} s_{i} k_{i}^{\hat{\alpha}} n_{i}^{\hat{\beta}-1}=\lambda_{n}
\end{aligned}
$$

where $\lambda_{k}, \lambda_{n}$ are the Lagrange multipliers associated with the two constraints. Therefore, the marginal product of capital and the marginal product of labor needs to be equated across firms. After some derivations (see Appendix) aggregate output can be decomposed as:

$$
Y=\underbrace{\frac{\sum_{i}\left(\frac{s_{i}}{\left(w_{i}^{k}\right)^{\hat{\alpha}}\left(w_{i}^{n}\right)^{\hat{\beta}}}\right)^{1 /(1-\gamma)}}{\Gamma} \Gamma^{1-\hat{\alpha}-\hat{\gamma}}}_{T F P} K^{\hat{\alpha}} N^{\hat{\beta}}
$$


where $w_{i}^{k}$ represents the wedge between the marginal product of capital and $\lambda_{k}$ for firm $i$, while $w_{i}^{n}$ represents the wedge between the marginal product of labor and $\lambda_{n}$. If $w_{i}^{k}=1$, $w_{i}^{n}=1$, then $Y=\Gamma^{1-\hat{\alpha}-\hat{\beta}} K^{\hat{\alpha}} N^{\hat{\beta}}$. In other words, this is the case when $\lambda_{k}=r+\delta$ and $\lambda_{n}=w$.

In our framework investment decisions $k^{\prime}$ are taken a period before productivity $z^{\prime}$ is realized. With sufficiently low persistence it is possible that capital is misallocated due to uncertainty over $z$. For this reason we construct an expected measure of TFP loss. In this calculation, we reallocate capital and labor across firms to maximize the expected level of output. That is, we take as given the stock of capital $K^{\prime}=\int k^{\prime} d \mu$ and next period's stock of labor $N^{\prime}=\int E\left[n^{\prime}\left(s^{\prime}\right)\right] d \mu$. We then allocate capital and labor across firms to maximize total expected output, subject to the constraint that the same amount of aggregate capital and labor are used as in the original equilibrium. In other words, taking as given $K^{\prime}$ and $N^{\prime}$ from the original economy, we solve the following problem:

$$
\max _{k_{i}^{\prime}, n_{i}^{\prime}\left(s_{i}^{\prime}\right)} \sum_{i} E\left[s_{i}^{\prime}\left(k_{i}^{\prime}\right)^{\hat{\alpha}}\left(n_{i}^{\prime}\left(s_{i}^{\prime}\right)\right)^{\hat{\beta}} \mid s_{i}\right]
$$

subject to

$$
\begin{aligned}
\sum_{i} k_{i}^{\prime} & =K^{\prime} \\
\sum_{i} E\left[n_{i}^{\prime}\left(s_{i}^{\prime}\right) \mid s_{i}\right] & =N^{\prime}
\end{aligned}
$$

In other words, for each firm $i$ we choose next period's capital $k_{i}^{\prime}$, and a rule for labor tomorrow $n_{i}^{\prime}\left(s_{i}^{\prime}\right)$ as a function of the realized value of productivity, $s_{i}^{\prime}$, to maximize expected aggregate output. The solution to this problem will require that the expected marginal product of capital be equated across firms, and that the marginal product of labor is equated across firms as well. In this case, the efficient expected level of output will be given by

$$
E\left[Y^{\prime}\right]=\left(\Gamma^{\prime}\right)^{1-\hat{\alpha}-\hat{\beta}}\left(K^{\prime}\right)^{\hat{\alpha}}\left(N^{\prime}\right)^{\hat{\beta}}
$$

where $\Gamma^{\prime} \equiv \sum_{i} E\left[\left(s_{i}^{\prime}\right)^{1 /(1-\hat{\beta})} \mid s_{i}\right]^{(1-\hat{\beta}) /(1-\gamma)} .\left(\Gamma^{\prime}\right)^{1-\hat{\alpha}-\hat{\beta}}$ is the efficient expected level of TFP.

The first order conditions are

$$
\begin{aligned}
& \lambda_{k}=E\left[\hat{\alpha} s_{i}^{\prime}\left(k_{i}^{\prime}\right)^{\hat{\alpha}-1} n_{i}^{\prime}\left(s_{i}^{\prime}\right)^{\hat{\beta}} \mid s_{i}\right] \\
& \lambda_{n}=\hat{\beta} s_{i}^{\prime}\left(k_{i}^{\prime}\right)^{\hat{\alpha}} n_{i}^{\prime}\left(s_{i}^{\prime}\right)^{\hat{\beta}-1}
\end{aligned}
$$

The expected marginal product of capital needs to be equated across firms, while the 
Figure 4: Simulated Marginal Product of Capital vs Productivity

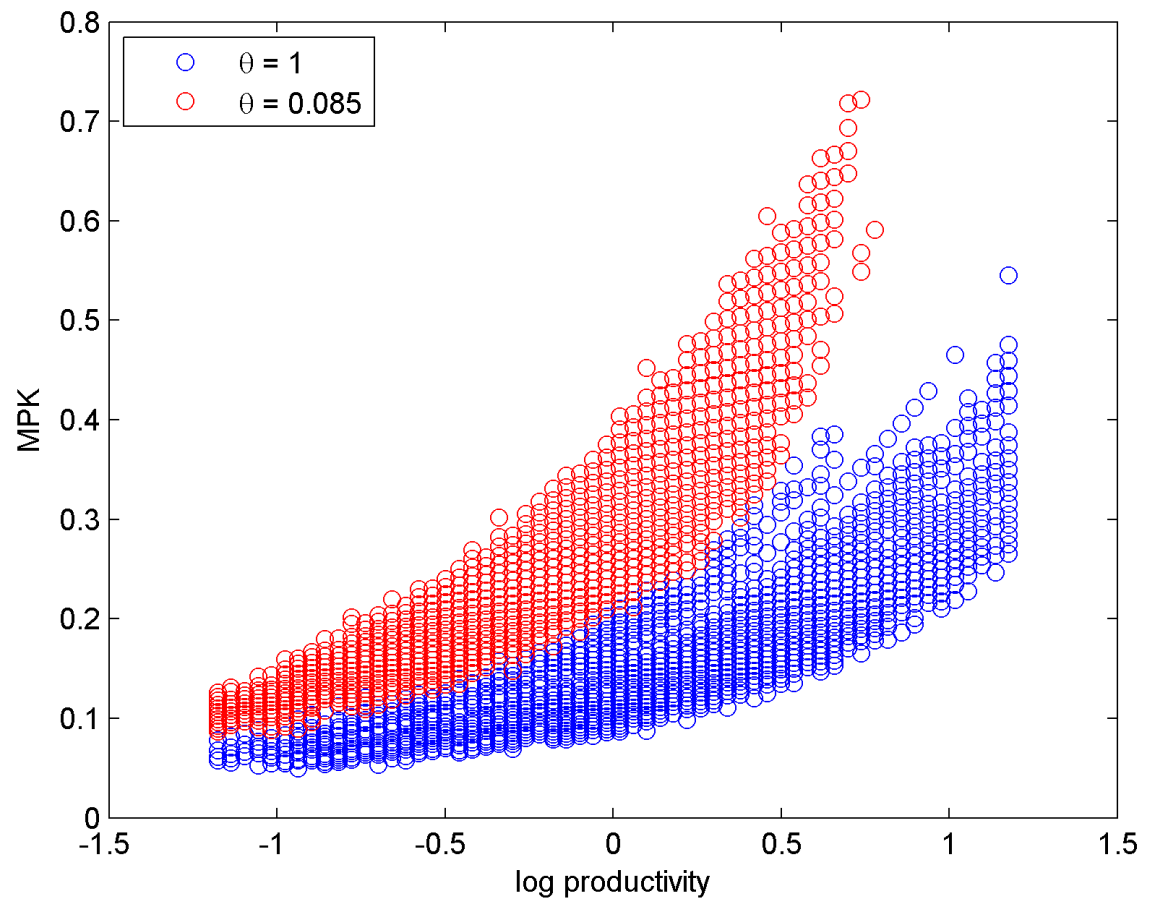

Note: This figure plots the simulated marginal product of capital against productivity for $\theta=1$ and $\theta=1 / 11.8$.

marginal product of labor is equated across firms. After some calculations we can derive the total expected output which is

$$
E\left[y_{i}^{\prime} \mid s_{i}\right]=\left(\frac{K^{\prime}}{\Gamma^{\prime}}\right)^{\hat{\alpha}}\left(\frac{N^{\prime}}{\Gamma^{\prime}}\right)^{\hat{\beta}} E\left[\left(s_{i}^{\prime}\right)^{1 /(1-\hat{\beta})} \mid s_{i}\right]^{1 \hat{-\hat{\beta} /(1-\gamma)}}
$$

\subsection{TFP losses from Misallocation}

We focus on two summary statistics that can affect misallocation. First, the standard deviation of marginal product of capital and second the correlation between marginal product of capital and productivity. To get a sense about these statistics, Figure 4 plots the simulated values of the marginal product of capital versus productivity. In the benchmark model the dispersion of MPK as well as the correlation between MPK and $z$ are higher than in the one period bond model.

In Table 5, we report the TFP loss in all models: benchmark, one-period bond and exogenous borrowing constraint as well as a model where all kind of frictions have been shut down. We report the TFP loss and the expected TFP loss as derived in the previous section. 
Table 5: Misallocation Statistics

\begin{tabular}{|c|c|c|c|c|}
\hline & Benchmark & $\begin{array}{l}\text { One-Period } \\
\text { Bond Model }\end{array}$ & $\begin{array}{c}\text { Exogenous Borrowing } \\
\text { Constraint Model }\end{array}$ & No Frictions \\
\hline \multicolumn{5}{|l|}{$\underline{\text { TFP loss }}$} \\
\hline All firms & $9.9 \%$ & $4.0 \%$ & $4.1 \%$ & $3.5 \%$ \\
\hline Bottom $95 \%$ in CS & $3.6 \%$ & $4.0 \%$ & $4.1 \%$ & $3.5 \%$ \\
\hline \multicolumn{5}{|c|}{ Standard Deviation of MPK } \\
\hline All firms & $10.5 \%$ & $4.9 \%$ & $4.9 \%$ & $4.2 \%$ \\
\hline Bottom $95 \%$ in CS & $9.0 \%$ & $4.0 \%$ & $4.1 \%$ & $3.5 \%$ \\
\hline \multicolumn{5}{|l|}{$\operatorname{Corr}(\log M P K, \log z)$} \\
\hline All firms & 0.81 & 0.87 & 0.87 & 0.75 \\
\hline Bottom $95 \%$ in CS & 0.94 & 0.87 & 0.87 & 0.95 \\
\hline \multicolumn{5}{|l|}{ Expected TFP loss } \\
\hline All firms & $6.5 \%$ & $0.4 \%$ & $0.5 \%$ & $0.0 \%$ \\
\hline Bottom $95 \%$ in CS & $1.0 \%$ & $0.4 \%$ & $0.5 \%$ & $0.0 \%$ \\
\hline \multicolumn{5}{|c|}{ Standard Deviation of MPK } \\
\hline All firms & $17.5 \%$ & $3.9 \%$ & $4.2 \%$ & $0.0 \%$ \\
\hline Bottom $95 \%$ in CS & $12.5 \%$ & $3.9 \%$ & $4.2 \%$ & $0.0 \%$ \\
\hline \multicolumn{5}{|l|}{$\operatorname{Corr}(\log M P K, \log z)$} \\
\hline All firms & 0.51 & 0.75 & 0.73 & 0.00 \\
\hline Bottom $95 \%$ in CS & 0.86 & 0.75 & 0.73 & 0.00 \\
\hline
\end{tabular}

Note: We report the TFP loss in all models: benchmark, one-period bond and exogenous borrowing constraint.

We also report separately the standard deviation of MPK and the correlation between MPK and productivity. In our benchmark model there is small fraction of firms that is diluting its debt is facing very high credit spreads. We thus separate our results further between all firms and firms in the bottom $95 \%$ of credit spread distribution.

Misallocation amounts to $9.9 \%$ TFP loss in our benchmark model as opposed to around $4.0 \%$ in the one-period model and the exogenous constraint model. If there are no frictions misallocation results to $3.5 \%$ loss which stems from firms making investment decisions before knowing next period's productivity. Hence, expected TFP loss from misallocation is $0.0 \%$ for the case with no frictions. In this case, the loss is $6.5 \%$ for our benchmark and around $0.5 \%$ for the one-period model and the exogenous constraint model.

In sum, our long-term financing model generates misallocation between 2.5 and 13 times higher relative to a one period bond model (or an exogenous constraint model). To understand this result we can compare the standard deviation of MKP between these models. In our benchmark model the standard deviation is $10.5 \%$ as opposed to $4.9 \%$ in the other two 
models. However, the correlation between MPK and $z$ is a little lower in the benchmark than the other two models but only if we include the top 5\% firms in the credit spread distribution. But the increase in the dispersion of MPK more than compensates the decline in the correlation (for all firms) so that the TFP loss increase overall.

\section{Conclusion}

We analyze the effect of financial frictions on misallocation in a model with long-term financing and endogenous investment. We show that our model can generate substantially larger dispersion in the marginal product of capital as well as larger correlation between productivity and marginal product of capital. In our setup productive firms may face higher credit spreads since they can easily refinance - and hence dilute - their current debt obligations. We find that misallocation is 3 times higher in our model compared to a model with a one-period bond or an exogenous collateral constraint. We conclude that the introduction of long-term financing (coupled with endogenous investment) is crucial to properly account for the effect of financial frictions on misallocation. 


\section{References}

Arellano, Christina, Yan Bai, and Jing Zhang. 2012. "Firm Dynamics and Financial Development"." Journal of Monetary Economics 59 (6):533-549.

Chatterjee, Satyajit and Burcu Eyigungor. 2012. "Maturity, Indebtedness, and Default Risk." American Economic Review 102 (6):2674-2699.

Clementi, Gian Luca and Berardino Palazzo. 2016. "Entry, Exit, Firm Dynamics, and Aggregate Fluctuations." American Economic Journal: Macroeconomics 8 (3):1-41.

Gilchrist, Simon, Jae W. Sim, and Egon Zakrajsek. 2012. "Misallocation and Financial Market Frictions: Some Direct evidence from the dispersion in borrowing costs." Review of Economic Dynamics 16 (1):159-176.

Hatchondo, Juan Carlos and Leonardo Martinez. 2009. "Long-duration Bonds and Sovereign Defaults." Journal of International Economics 79 (1):117-125.

Hennessy, Christopher A. and Toni M. Whited. 2007. "How Costly Is External Financing? Evidence from a Structural Estimation.” Journal of Finance 62 (4):1705-1745.

Hsieh, Chang-Tai and Peter J. Klenow. 2009. "Misallocation and Manufacturing TFP in China and India." Quarterly Journal of Economics 124 (4):1403-1448.

Katagiri, Mitsuru. 2014. "A Macroeconomic Approach to Corporate Capital Structure." Journal of Monetary Economics 66:79-94.

Khan, Aubhik and Julia K. Thomas. 2013. "Credit shocks and Aggregate Fluctuations in an Economy with Production Heterogeneity." Journal of Political Economy 121 (6).

Midrigan, Virgiliu and Daniel Yi Xu. 2014. "Finance and Misallocation:Evidene from plantlevel data." American Economic Review 104 (2):422-458.

Moll, Benjamin. 2014. "Productivity losses from financial frictions:Can self-financing undo capital misallocation?" American Economic Review 104 (10):3186-3221. 


\section{A Appendix}

\section{A.1 Misallocation}

First, we compute the size of TFP losses that arise due to the misallocation of capital and labor across firms. To compute TFP losses, we take as given the total stock of capital $K=\int k d \mu$ and the total stock of labor $N=\int n d \mu$ in the economy. We then allocate capital and labor across firms to maximize total output, subject to the constraint that the same amount of aggregate capital and labor are used as in the original economy. In other words, taking as given the aggregate stock of capital $K$ and labor $N$ from the original economy, we solve the following problem:

$$
\max _{k_{i}, n_{i}} \sum_{i} s_{i} k_{i}^{\hat{\alpha}} n_{i}^{\hat{\beta}}
$$

subject to

$$
\begin{aligned}
& \sum_{i} k_{i}=K \\
& \sum_{i} n_{i}=N
\end{aligned}
$$

The solution to this problem requires that the marginal product of capital and the marginal product of labor are equated across firms. In this case, the efficient level of output will be given by

$$
Y_{e}=\Gamma^{1-\hat{\alpha}-\hat{\beta}} K^{\hat{\alpha}} N^{\hat{\beta}}
$$

where $\Gamma=\sum_{i} s_{i}^{1 /(1-\gamma)} . \Gamma^{1-\hat{\alpha}-\hat{\beta}}$ is the efficient level of TFP.

Given production function $f(s, k, n)=s\left[k^{\alpha} n^{1-\alpha}\right]^{\gamma}=s k^{\hat{\alpha}} n^{\hat{\beta}}$, aggregate output in equilibrium is given by

$$
Y=\int f(s, k, n(s, k ; w)) d \mu
$$

where $\mu(s, k, b)$ is the stationary distribution of firms.

Solving $f_{n}=w$, labor demand is:

$$
n^{d}(s, k ; w)=\left(\frac{\hat{\beta}}{w} s k^{\hat{\alpha}}\right)^{1 /(1-\hat{\beta})}
$$


The output of a firm, given productivity $s$, capital $k$ and wage $w$ is then:

$$
\begin{aligned}
f(s, k, n(s, k ; w)) & =s k^{\hat{\alpha}} n^{\hat{\beta}} \\
& =s k^{\hat{\alpha}}\left[\frac{\hat{\beta}}{w} s k^{\hat{\alpha}}\right]^{\hat{\beta} /(1-\hat{\beta})} \\
& =\left(\frac{\hat{\beta}}{w}\right)^{\hat{\beta} /(1-\hat{\beta})}\left(s k^{\hat{\alpha}}\right)^{1 /(1-\hat{\beta})}
\end{aligned}
$$

Profits of the firm are

$$
\pi(s, k ; w)=(1-\hat{\beta})\left(\frac{\hat{\beta}}{w}\right)^{\hat{\beta} /(1-\hat{\beta})}\left(s k^{\hat{\alpha}}\right)^{1 /(1-\hat{\beta})}
$$

Defining $z=s^{1 /(1-\hat{\beta})}, b=\hat{\alpha} /(1-\hat{\beta})$, and $A=(1-\hat{\beta})\left(\frac{\hat{\beta}}{w}\right)^{\hat{\beta} /(1-\hat{\beta})}$, then profits can be written as

$$
\pi(z, k)=A z k^{b}
$$

Output $y(z, k)$ can be written as

$$
y(z, k)=C z k^{b}
$$

where $C=\left(\frac{\hat{\beta}}{w}\right)^{\hat{\beta} /(1-\hat{\beta})}$.

To study misallocation, we want to reallocate capital and labor between firms. In other words, given the existing distribution of capital, we want to solve

$$
\max _{k_{i}, n_{i}} \sum_{i \in \mu} s_{i} k_{i}^{\hat{\alpha}} n_{i}^{\hat{\beta}}
$$

subject to

$$
\begin{aligned}
& \sum_{i} k_{i}=K \\
& \sum_{i} n_{i}=N
\end{aligned}
$$

where $K$ and $N$ are the current aggregate capital and labor stocks. Essentially, we are just reallocating capital and labor across firms to increase total output. 
Lagrangian:

$$
\mathcal{L}=\sum_{i} s_{i} k_{i}^{\hat{\alpha}} n_{i}^{\hat{\beta}}+\lambda_{k}\left[K-\sum_{i} k_{i}\right]+\lambda_{n}\left[N-\sum_{i} n_{i}\right]
$$

First order conditions:

$$
\begin{gathered}
\hat{\alpha} s_{i} k_{i}^{\hat{\alpha}-1} n_{i}^{\hat{\beta}}=\lambda_{k} \\
\hat{\beta} s_{i} k_{i}^{\hat{\alpha}} n_{i}^{\hat{\beta}-1}=\lambda_{n}
\end{gathered}
$$

Therefore, the marginal product of capital and the marginal product of labor needs to be equated across firms.

Solving Equation 8 for $k_{i}$, we get:

$$
k_{i}=\left(\frac{\hat{\alpha} s_{i} n_{i}^{\hat{\beta}}}{\lambda_{k}}\right)^{1 /(1-\hat{\alpha})}
$$

Similarly, solving Equation 9 for $n_{i}$, we get:

$$
n_{i}=\left(\frac{\hat{\beta} s_{i} k_{i}^{\hat{\alpha}}}{\lambda_{n}}\right)^{1 /(1-\hat{\beta})}
$$

Solving Equations 10 and 11 for $k_{i}$ and $n_{i}$, we get:

$$
\begin{aligned}
& k_{i}=\left(\frac{\hat{\alpha}}{\lambda_{k}}\right)^{\frac{1-\hat{\beta}}{1-\gamma}}\left(\frac{\hat{\beta}}{\lambda_{n}}\right)^{\frac{\hat{\beta}}{1-\gamma}} s_{i}^{\frac{1}{1-\gamma}} \\
& n_{i}=\left(\frac{\hat{\alpha}}{\lambda_{k}}\right)^{\frac{\hat{\alpha}}{1-\gamma}}\left(\frac{\hat{\beta}}{\lambda_{n}}\right)^{\frac{1-\hat{\alpha}}{1-\gamma}} s_{i}^{\frac{1}{1-\gamma}}
\end{aligned}
$$

Then, substituting Equations 12 and 13 into $\sum_{i} k_{i}=K$ and $\sum_{i} n_{i}=N$, respectively, we get:

$$
\begin{aligned}
& \left(\frac{\hat{\alpha}}{\lambda_{k}}\right)^{\frac{1-\hat{\beta}}{1-\gamma}}\left(\frac{\hat{\beta}}{\lambda_{n}}\right)^{\frac{\hat{\beta}}{1-\gamma}} \Gamma=K \\
& \left(\frac{\hat{\alpha}}{\lambda_{k}}\right)^{\frac{\hat{\alpha}}{1-\gamma}}\left(\frac{\hat{\beta}}{\lambda_{n}}\right)^{\frac{1-\hat{\alpha}}{1-\gamma}} \Gamma=N
\end{aligned}
$$


where $\Gamma \equiv \sum_{i} s_{i}^{1 /(1-\gamma)}$. Solving Equations 14 and 15 for $\lambda_{k}$ and $\lambda_{n}$ yields

$$
\begin{aligned}
& \lambda_{k}=\hat{\alpha} K^{\hat{\alpha}-1} N^{\hat{\beta}} \Gamma^{1-\gamma} \\
& \lambda_{n}=\hat{\beta} K^{\hat{\alpha}} N^{\hat{\beta}-1} \Gamma^{1-\gamma}
\end{aligned}
$$

Substituting Equations 16 and 17 into Equations 12 and 13 yields

$$
\begin{aligned}
k_{i} & =\left(\frac{K}{\Gamma}\right) s_{i}^{1 /(1-\gamma)} \\
n_{i} & =\left(\frac{N}{\Gamma}\right) s_{i}^{1 /(1-\gamma)}
\end{aligned}
$$

Compare this to allocation where $M P K=r+\delta$ and $M P N=w$. In that case,

$$
\begin{aligned}
& k=\left(\frac{\hat{\alpha}}{r+\delta}\right)^{\frac{1-\hat{\beta}}{1-\gamma}}\left(\frac{\hat{\beta}}{w}\right)^{\frac{\hat{\beta}}{1-\gamma}} s^{\frac{1}{1-\gamma}} \\
& n=\left(\frac{\hat{\alpha}}{r+\delta}\right)^{\frac{\hat{\alpha}}{1-\gamma}}\left(\frac{\hat{\beta}}{w}\right)^{\frac{1-\hat{\alpha}}{1-\gamma}} s^{\frac{1}{1-\gamma}}
\end{aligned}
$$

In other words, this is the case when $\lambda_{k}=r+\delta$ and $\lambda_{n}=w$.

Suppose that for a given choice $\left(k_{i}, n_{i}\right) M P K=\lambda_{k} w_{i}^{k}$ and $M P N=\lambda_{n} w_{i}^{n}$. In this case, $w_{i}^{k}$ represents the wedge between the marginal product of capital and $\lambda_{k}$ for firm $i$, while $w_{i}^{n}$ represents the wedge between the marginal product of labor and $\lambda_{n}$. In this case, aggregate output can be decomposed as:

$$
Y=\underbrace{\frac{\sum_{i}\left(\frac{s_{i}}{\left(w_{i}^{k}\right)^{\hat{\alpha}}\left(w_{i}^{n}\right)^{\hat{\beta}}}\right)^{1 /(1-\gamma)}}{\Gamma} \Gamma^{1-\hat{\alpha}-\hat{\gamma}}}_{\text {TFP }} K^{\hat{\alpha}} N^{\hat{\beta}}
$$

If $w_{i}^{k}=1, w_{i}^{n}=1$, then $Y=\Gamma^{1-\hat{\alpha}-\hat{\beta}} K^{\hat{\alpha}} N^{\hat{\beta}}$.

\section{A.2 Expected Misallocation}

We also compute an expected measure of TFP loss. In this calculation, we reallocate capital and labor across firms to maximize the expected level of output. That is, we take as given the stock of capital $K^{\prime}=\int k^{\prime} d \mu$ and next period's stock of labor $N^{\prime}=\int E\left[n^{\prime}\left(s^{\prime}\right)\right] d \mu$. We then allocate capital and labor across firms to maximize total expected output, subject to the constraint that the same amount of aggregate capital and labor are used as in the 
original equilibrium. In other words, taking as given $K^{\prime}$ and $N^{\prime}$ from the original economy, we solve the following problem:

$$
\max _{k_{i}^{\prime}, n_{i}^{\prime}\left(s_{i}^{\prime}\right)} \sum_{i} E\left[s_{i}^{\prime}\left(k_{i}^{\prime}\right)^{\hat{\alpha}}\left(n_{i}^{\prime}\left(s_{i}^{\prime}\right)\right)^{\hat{\beta}} \mid s_{i}\right]
$$

subject to

$$
\begin{aligned}
\sum_{i} k_{i}^{\prime} & =K^{\prime} \\
\sum_{i} E\left[n_{i}^{\prime}\left(s_{i}^{\prime}\right) \mid s_{i}\right] & =N^{\prime}
\end{aligned}
$$

In other words, for each firm $i$ we choose next period's capital $k_{i}^{\prime}$, and a rule for labor tomorrow $n_{i}^{\prime}\left(s_{i}^{\prime}\right)$ as a function of the realized value of productivity, $s_{i}^{\prime}$, to maximize expected aggregate output. The solution to this problem will require that the expected marginal product of capital be equated across firms, and that the marginal product of labor is equated across firms as well. In this case, the efficient expected level of output will be given by

$$
E\left[Y^{\prime}\right]=\left(\Gamma^{\prime}\right)^{1-\hat{\alpha}-\hat{\beta}}\left(K^{\prime}\right)^{\hat{\alpha}}\left(N^{\prime}\right)^{\hat{\beta}}
$$

where $\Gamma^{\prime} \equiv \sum_{i} E\left[\left(s_{i}^{\prime}\right)^{1 /(1-\hat{\beta})} \mid s_{i}\right]^{(1-\hat{\beta}) /(1-\gamma)} .\left(\Gamma^{\prime}\right)^{1-\hat{\alpha}-\hat{\beta}}$ is the efficient expected level of TFP.

Objective:

$$
\max _{k_{i}^{\prime}, n_{i}^{\prime}\left(s_{i}^{\prime}\right)} \sum_{i} E\left[s_{i}^{\prime}\left(k_{i}^{\prime}\right)^{\hat{\alpha}}\left(n_{i}^{\prime}\left(s_{i}^{\prime}\right)\right)^{\hat{\beta}} \mid s_{i}\right]
$$

subject to

$$
\begin{aligned}
\sum_{i} k_{i}^{\prime} & =K^{\prime} \\
\sum_{i} E\left[n_{i}^{\prime}\left(s_{i}^{\prime}\right) \mid s_{i}\right] & =N^{\prime}
\end{aligned}
$$

That is, we want to re-allocate $k_{i}^{\prime}$ and $n_{i}^{\prime}$ to maximize expected output. Choose rule for $n_{i}^{\prime}$ as a function of $s_{i}^{\prime}$.

Lagrangian:

$$
\mathcal{L}=\sum_{i} \sum_{s_{i}^{\prime}} \pi\left(s_{i}^{\prime} \mid s_{i}\right)\left[s_{i}^{\prime}\left(k_{i}^{\prime}\right)^{\hat{\alpha}}\left(n_{i}^{\prime}\left(s_{i}^{\prime}\right)\right)^{\hat{\beta}}\right]+\lambda_{k}\left[K^{\prime}-\sum_{i} k_{i}^{\prime}\right]+\lambda_{n}\left[N^{\prime}-\sum_{i} \sum_{s_{i}^{\prime}} \pi\left(s_{i}^{\prime} \mid s_{i}\right) n_{i}^{\prime}\left(s_{i}^{\prime}\right)\right]
$$


First order conditions:

$$
\begin{aligned}
& \lambda_{k}=E\left[\hat{\alpha} s_{i}^{\prime}\left(k_{i}^{\prime}\right)^{\hat{\alpha}-1} n_{i}^{\prime}\left(s_{i}^{\prime}\right)^{\hat{\beta}} \mid s_{i}\right] \\
& \lambda_{n}=\hat{\beta} s_{i}^{\prime}\left(k_{i}^{\prime}\right)^{\hat{\alpha}} n_{i}^{\prime}\left(s_{i}^{\prime}\right)^{\hat{\beta}-1}
\end{aligned}
$$

The expected marginal product of capital needs to be equated across firms, while the marginal product of labor is equated across firms.

Solving Equation (21) for $n_{i}^{\prime}\left(s_{i}^{\prime}\right)$, we get:

$$
n_{i}^{\prime}\left(s_{i}^{\prime}\right)=\left[\frac{\hat{\beta} s_{i}^{\prime}\left(k_{i}^{\prime}\right)^{\hat{\alpha}}}{\lambda_{n}}\right]^{1 /(1-\hat{\beta})}
$$

Substituting into the FOC for $k_{i}^{\prime}$ :

$$
\begin{aligned}
& \lambda_{k}=E\left[\hat{\alpha} s_{i}^{\prime}\left(k_{i}^{\prime}\right)^{\hat{\alpha}-1}\left[\frac{\hat{\beta} s_{i}^{\prime}\left(k_{i}^{\prime}\right)^{\hat{\alpha}}}{\lambda_{n}}\right]^{\hat{\beta} /(1-\hat{\beta})} \mid s_{i}\right] \\
& 1=\left(\frac{\hat{\alpha}}{\lambda_{k}}\right)\left(\frac{\hat{\beta}}{\lambda_{n}}\right)^{\hat{\beta} /(1-\hat{\beta})} E\left[\frac{\left(s_{i}^{\prime}\left(k_{i}^{\prime}\right)^{\hat{\alpha}}\right)^{1 /(1-\hat{\beta})}}{k_{i}^{\prime}} \mid s_{i}\right]
\end{aligned}
$$

Solving for $k_{i}^{\prime}$ :

$$
\begin{aligned}
& k_{i}^{\prime}=\left\{\left(\frac{\hat{\alpha}}{\lambda_{k}}\right)\left(\frac{\hat{\beta}}{\lambda_{n}}\right)^{\hat{\beta} /(1-\hat{\beta})} E\left[\left(s_{i}^{\prime}\right)^{1 /(1-\hat{\beta})} \mid s_{i}\right]\right\}^{1 /\left(1-\frac{\hat{\alpha}}{1-\hat{\beta}}\right)} \\
& k_{i}^{\prime}=\left\{\left(\frac{\hat{\alpha}}{\lambda_{k}}\right)\left(\frac{\hat{\beta}}{\lambda_{n}}\right)^{\hat{\beta} /(1-\hat{\beta})} E\left[\left(s_{i}^{\prime}\right)^{1 /(1-\hat{\beta})} \mid s_{i}\right]\right\}^{\frac{1-\hat{\beta}}{1-\gamma}} \\
& k_{i}^{\prime}=\left(\frac{\hat{\alpha}}{\lambda_{k}}\right)^{\frac{1-\hat{\beta}}{1-\gamma}}\left(\frac{\hat{\beta}}{\lambda_{n}}\right)^{\frac{\hat{\beta}}{1-\gamma}} E\left[\left(s_{i}^{\prime}\right)^{1 /(1-\hat{\beta})} \mid s_{i}\right]^{\frac{1-\hat{\beta}}{1-\gamma}}
\end{aligned}
$$


Substitute for $k_{i}^{\prime}$ in Equation (22):

$$
\begin{aligned}
& n_{i}^{\prime}\left(s_{i}^{\prime}\right)=\left[\frac{\hat{\beta} s_{i}^{\prime}\left(k_{i}^{\prime}\right)^{\hat{\alpha}}}{\lambda_{n}}\right]^{1 /(1-\hat{\beta})} \\
& n_{i}^{\prime}\left(s_{i}^{\prime}\right)=\left(\frac{\hat{\beta}}{\lambda_{n}}\right)^{\frac{1}{1-\hat{\beta}}}\left(s_{i}^{\prime}\right)^{1 /(1-\hat{\beta})}\left(\frac{\hat{\alpha}}{\lambda_{k}}\right)^{\frac{1-\hat{\beta}}{1-\gamma} \frac{\hat{\alpha}}{1-\beta}}\left(\frac{\hat{\beta}}{\lambda_{n}}\right)^{\frac{\hat{\beta}}{1-\gamma} \frac{\hat{\alpha}}{1-\hat{\beta}}} E\left[\left(s_{i}^{\prime}\right)^{1 /(1-\hat{\beta})} \mid s_{i}\right]^{\frac{1-\hat{\beta}}{1-\gamma} \frac{\hat{\alpha}}{1-\hat{\beta}}} \\
& n_{i}^{\prime}\left(s_{i}^{\prime}\right)=\left(\frac{\hat{\beta}}{\lambda_{n}}\right)^{\frac{1}{1-\hat{\beta}}}\left(s_{i}^{\prime}\right)^{1 /(1-\hat{\beta})}\left(\frac{\hat{\alpha}}{\lambda_{k}}\right)^{\frac{\hat{\alpha}}{1-\gamma}}\left(\frac{\hat{\beta}}{\lambda_{n}}\right)^{\frac{\hat{\beta}}{1-\gamma} \frac{\hat{\alpha}}{1-\hat{\beta}}} E\left[\left(s_{i}^{\prime}\right)^{1 /(1-\hat{\beta})} \mid s_{i}\right]^{\frac{\hat{\alpha}}{1-\gamma}} \\
& n_{i}^{\prime}\left(s_{i}^{\prime}\right)=\left(\frac{\hat{\alpha}}{\lambda_{k}}\right)^{\frac{\hat{\alpha}}{1-\gamma}}\left(\frac{\hat{\beta}}{\lambda_{n}}\right)^{\frac{1-\hat{\alpha}}{1-\gamma}}\left(s_{i}^{\prime}\right)^{1 /(1-\hat{\beta})} E\left[\left(s_{i}^{\prime}\right)^{1 /(1-\hat{\beta})} \mid s_{i}\right]^{\frac{\hat{\alpha}}{1-\gamma}}
\end{aligned}
$$

Take expectations to get the expected value of $n_{i}^{\prime}$ tomorrow:

$$
E\left[n_{i}^{\prime}\left(s_{i}^{\prime}\right) \mid s_{i}\right]=\left(\frac{\hat{\alpha}}{\lambda_{k}}\right)^{\frac{\hat{\alpha}}{1-\gamma}}\left(\frac{\hat{\beta}}{\lambda_{n}}\right)^{\frac{1-\hat{\alpha}}{1-\gamma}} E\left[\left(s_{i}^{\prime}\right)^{1 /(1-\hat{\beta})} \mid s_{i}\right]^{\frac{1-\hat{\beta}}{1-\gamma}}
$$

Substitute for $k_{i}^{\prime}$ and $E\left[n_{i}^{\prime}\left(s_{i}^{\prime}\right) \mid s_{i}\right]$ in the constraints:

$$
\begin{array}{r}
\sum_{i} k_{i}^{\prime}=K^{\prime} \\
\left(\frac{\hat{\alpha}}{\lambda_{k}}\right)^{\frac{1-\hat{\beta}}{1-\gamma}}\left(\frac{\hat{\beta}}{\lambda_{n}}\right)^{\frac{\hat{\beta}}{1-\gamma}} \sum_{i} E\left[\left(s_{i}^{\prime}\right)^{1 /(1-\hat{\beta})} \mid s_{i}\right]^{\frac{1-\hat{\beta}}{1-\gamma}}=K^{\prime}
\end{array}
$$

Define:

$$
\Gamma^{\prime} \equiv \sum_{i} E\left[\left(s_{i}^{\prime}\right)^{1 /(1-\hat{\beta})} \mid s_{i}\right]^{\frac{1-\hat{\beta}}{1-\gamma}}
$$

Then, we have:

$$
\left(\frac{\hat{\alpha}}{\lambda_{k}}\right)^{\frac{1-\hat{\beta}}{1-\gamma}}\left(\frac{\hat{\beta}}{\lambda_{n}}\right)^{\frac{\hat{\beta}}{1-\gamma}} \Gamma^{\prime}=K^{\prime}
$$


Substitute for the optimal $E\left[n_{i}^{\prime}\left(s_{i}^{\prime}\right) \mid s_{i}\right]$ in the constraint:

$$
\begin{aligned}
\sum_{i} E\left[n_{i}^{\prime}\left(s_{i}^{\prime}\right) \mid s_{i}\right] & =N^{\prime} \\
\left(\frac{\hat{\alpha}}{\lambda_{k}}\right)^{\frac{\hat{\alpha}}{1-\gamma}}\left(\frac{\hat{\beta}}{\lambda_{n}}\right)^{\frac{1-\hat{\alpha}}{1-\gamma}} \sum_{i} E\left[\left(s_{i}^{\prime}\right)^{1 /(1-\hat{\beta})} \mid s_{i}\right]^{\frac{1-\hat{\beta}}{1-\gamma}} & =N^{\prime} \\
\left(\frac{\hat{\alpha}}{\lambda_{k}}\right)^{\frac{\hat{\alpha}}{1-\gamma}}\left(\frac{\hat{\beta}}{\lambda_{n}}\right)^{\frac{1-\hat{\alpha}}{1-\gamma}} \Gamma^{\prime} & =N^{\prime}
\end{aligned}
$$

Solving Equations (26) and (27) for $\lambda_{k}$ and $\lambda_{n}$ :

$$
\begin{aligned}
& \lambda_{k}=\hat{\alpha}\left(K^{\prime}\right)^{\hat{\alpha}-1}\left(N^{\prime}\right)^{\hat{\beta}}\left(\Gamma^{\prime}\right)^{1-\gamma} \\
& \lambda_{n}=\hat{\beta}\left(K^{\prime}\right)^{\hat{\alpha}}\left(N^{\prime}\right)^{\hat{\beta}-1}\left(\Gamma^{\prime}\right)^{1-\gamma}
\end{aligned}
$$

Substituting for $\lambda_{k}$ and $\lambda_{n}$ in Equation (23):

$$
k_{i}^{\prime}=\left(\frac{K^{\prime}}{\Gamma^{\prime}}\right) E\left[\left(s_{i}^{\prime}\right)^{1 /(1-\hat{\beta})} \mid s_{i}\right]^{\frac{1-\hat{\beta}}{1-\gamma}}
$$

Using Equation 27, substitute for $\lambda_{k}$ and $\lambda_{n}$ in Equation (24), labor $n_{i}^{\prime}$ is then:

$$
n_{i}^{\prime}\left(s_{i}^{\prime}\right)=\frac{N^{\prime}}{\Gamma^{\prime}}\left(s_{i}^{\prime}\right)^{1 /(1-\hat{\beta})} E\left[\left(s_{i}^{\prime}\right)^{1 /(1-\hat{\beta})} \mid s_{i}\right]^{\frac{\hat{\alpha}}{1-\gamma}}
$$

Taking expectations:

$$
E\left[n_{i}^{\prime}\left(s_{i}^{\prime}\right) \mid s_{i}\right]=\frac{N^{\prime}}{\Gamma^{\prime}} E\left[\left(s_{i}^{\prime}\right)^{1 /(1-\hat{\beta})} \mid s_{i}\right]^{\frac{1-\hat{\beta}}{1-\gamma}}
$$

Output is then:

$$
\begin{aligned}
& y_{i}^{\prime}=s_{i}^{\prime}\left(k_{i}^{\prime}\right)^{\hat{\alpha}} n_{i}^{\prime}\left(s_{i}^{\prime}\right)^{\hat{\beta}} \\
& y_{i}^{\prime}=s_{i}^{\prime}\left(k_{i}^{\prime}\right)^{\hat{\alpha}}\left(\frac{\hat{\beta}}{\lambda_{n}} s_{i}^{\prime}\left(k_{i}^{\prime}\right)^{\hat{\alpha}}\right)^{\frac{\hat{\beta}}{1-\hat{\beta}}} \\
& y_{i}^{\prime}=\left(\frac{\hat{\beta}}{\lambda_{n}}\right)^{\frac{\hat{\beta}}{1-\hat{\beta}}}\left[s_{i}^{\prime}\left(k_{i}^{\prime}\right)^{\hat{\alpha}}\right]^{\frac{1}{1-\hat{\beta}}}
\end{aligned}
$$


Taking expectations:

$$
E\left[y_{i}^{\prime} \mid s_{i}\right]=\left(\frac{\hat{\beta}}{\lambda_{n}}\right)^{\frac{\hat{\beta}}{1-\hat{\beta}}}\left[k_{i}^{\prime}\right]^{\frac{\hat{\alpha}}{1-\hat{\beta}}} E\left[\left(s_{i}^{\prime}\right)^{1 /(1-\hat{\beta})} \mid s_{i}\right]
$$

Alternatively, we can substitute for $k_{i}^{\prime}$ and $n_{i}^{\prime}\left(s_{i}^{\prime}\right)$ as follows:

$$
\begin{aligned}
& y_{i}^{\prime}=s_{i}^{\prime}\left(k_{i}^{\prime}\right)^{\hat{\alpha}} n_{i}^{\prime}\left(s_{i}^{\prime}\right)^{\hat{\beta}} \\
& y_{i}^{\prime}=\left(\frac{K^{\prime}}{\Gamma^{\prime}}\right)^{\hat{\alpha}}\left(\frac{N^{\prime}}{\Gamma^{\prime}}\right)^{\hat{\beta}}\left(s_{i}^{\prime}\right)^{1 /(1-\hat{\beta})} E\left[\left(s_{i}^{\prime}\right)^{1 /(1-\hat{\beta})} \mid s_{i}\right]^{\hat{\alpha} /(1-\gamma)}
\end{aligned}
$$

Taking expectations:

$$
E\left[y_{i}^{\prime} \mid s_{i}\right]=\left(\frac{K^{\prime}}{\Gamma^{\prime}}\right)^{\hat{\alpha}}\left(\frac{N^{\prime}}{\Gamma^{\prime}}\right)^{\hat{\beta}} E\left[\left(s_{i}^{\prime}\right)^{1 /(1-\hat{\beta})} \mid s_{i}\right]^{1 \hat{-\hat{\beta}} /(1-\gamma)}
$$

Aggregating across all firms, total expected output is then

$$
E\left[Y^{\prime}\right]=\left(K^{\prime}\right)^{\hat{\alpha}}\left(N^{\prime}\right)^{\hat{\beta}}\left(\Gamma^{\prime}\right)^{1-\hat{\alpha}-\hat{\beta}}
$$

